Florida International University FIU Digital Commons

6-8-2017

\title{
Development of Novel, Microscale Fracture Toughness Testing for Adhesives
}

Dillon S. Watring

Florida International University, dwatr001@fiu.edu

DOI: $10.25148 /$ etd.FIDC001921

Follow this and additional works at: https://digitalcommons.fiu.edu/etd

Part of the Other Materials Science and Engineering Commons, and the Other Mechanical Engineering Commons

\section{Recommended Citation}

Watring, Dillon S., "Development of Novel, Microscale Fracture Toughness Testing for Adhesives" (2017). FIU Electronic Theses and Dissertations. 3474.

https://digitalcommons.fiu.edu/etd/3474 


\section{FLORIDA INTERNATIONAL UNIVERSITY}

Miami, Florida

DEVELOPMENT OF NOVEL, MICROSCALE FRACTURE TOUGHNESS TESTING FOR ADHESIVES

A thesis submitted in partial fulfillment of the

requirements for the degree of

MASTER OF SCIENCE

in

MECHANICAL ENGINEERING

by

Dillon Scott Watring 
To: Interim Dean Ranu Jung

College of Engineering and Computing

This thesis, written by Dillon Scott Watring, and entitled Development of Novel, Microscale Fracture Toughness Testing for Adhesives, having been approved in respect to style and intellectual content, is referred to you for judgment.

We have read this thesis and recommend that it be approved.

Dwayne McDaniel

Sakhrat Khizroev

Benjamin Boesl, Major Professor

Date of Defense: June 8, 2017

The thesis of Dillon Scott Watring is approved.

Interim Dean Ranu Jung College of Engineering and Computing

Dean Andrés G. Gil

Vice President for Research and Economic Development and Dean of the University Graduate School

Florida International University, 2017 


\section{DEDICATION}

I would like to dedicate this thesis to my entire family. Specifically, my mother who has always been my comforter, my friend, my shoulder to cry on, and my super hero. My Papa and Mimi, who helped raise me and helped me become the person I am today. I would also like to dedicate it to all my loving aunts and uncles, who have provided me with priceless guidance and support throughout my life. 


\section{ACKNOWLEDGMENTS}

I would like to acknowledge and sincerely thank all who contributed to the work presented in this thesis. I would like to specifically acknowledge Dr. Benjamin Boesl for his guidance, support, and advice during my academic career here at FIU. Dr. Boesl introduced me to research as an undergraduate and allowed me to continue research while pursuing M.S. in mechanical engineering. He provided me with an in depth understanding and passion for research and academia. Additionally, I would like to specifically thank Dr. Dwayne McDaniel who provided countless amounts of support and guidance. I hope everyone gets an opportunity to have amazing mentors like Dr. Boesl and Dr. McDaniel. I would also I would also like to acknowledge and thank Dr. Sakhrat Khizroev who provided important support and knowledge for this thesis. I would like to thank all my peers that made my research career here at FIU enjoyable and friends that kept me from going mad; Jorge Coria, Kao Yang, Anthony Abrahao, and any others I may have missed. I would like to thank everyone at the Applied Research Center for their help and friendship. Finally, I would like to thank the Office of Naval Research and William Nickerson for the funding for this project (ONR FA8650-13-C-5800). 


\section{ABSTRACT OF THE THESIS \\ DEVELOPMENT OF NOVEL, MICROSCALE FRACTURE TOUGHNESS TESTING \\ FOR ADHESIVES}

by

\section{Dillon Scott Watring}

Florida International University, 2017

Miami, Florida

Professor Benjamin Boesl, Major Professor

The purpose of this thesis was to develop microscale fracture toughness tests to be performed in situ based off previously used macroscale fracture toughness tests. The thesis also was to use these tests to perform in situ analysis and imaging of reinforced adhesives during crack propagation. Two different fracture toughness tests were developed for this thesis through developing fixtures and sample geometry. A microscale double cantilever beam (DCB) test was developed for mode I fracture (opening mode). A microscale end notch flexure (ENF) test was developed for mode II fracture (sliding mode).

Three different types of materials were used as a reinforcing agent and tested using the micro-DCB and micro-ENF tests. Magnetoelectric nanoparticles (MENs) doped adhesive showed a $12 \%$ increase in mode I toughness and $33 \%$ increase in total fracture energy for micro-DCB. Similarly, the graphene foam $(\mathrm{GrF})$ doped adhesive showed an approximate $34 \%$ increase in mode I toughness and a $71 \%$ increase in total fracture energy for mode I. In situ imaging provided real time imaging of crack propagation for all three reinforcing agents that allowed for a novel analysis of the crack propagation and general fracture. 
CHAPTER

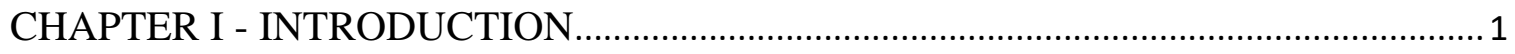

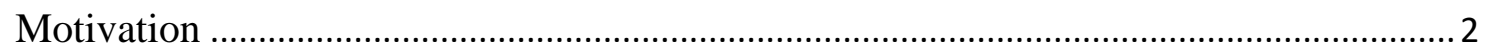

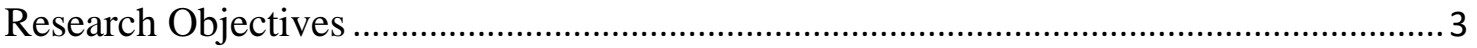

CHAPTER II - LITERATURE REVIEW ………………………………………....

Review of Fracture Mechanics ..........................................................................

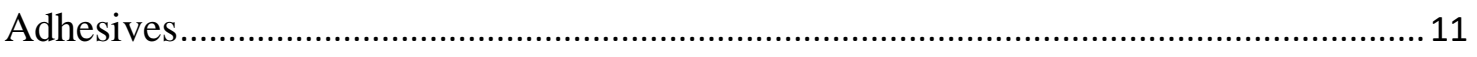

Double Cantilever Beam........................................................................................... 12

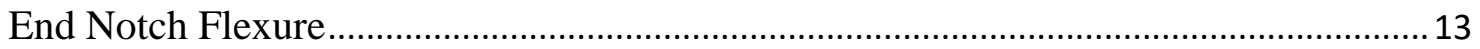

Adhesive Reinforcing Agents ................................................................................ 14

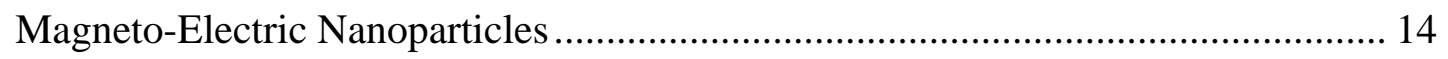

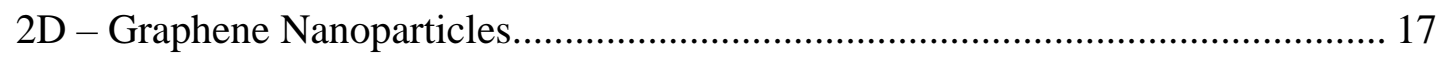

3D - Graphene Foam ....................................................................................... 19

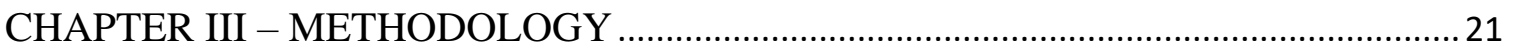

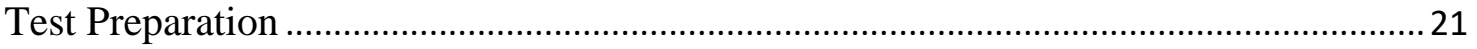

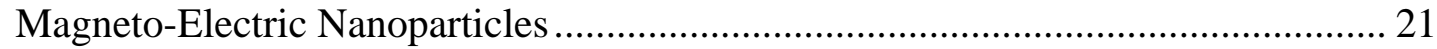

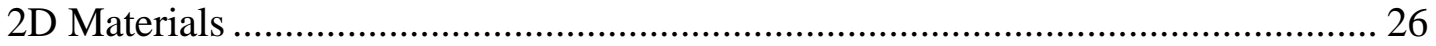

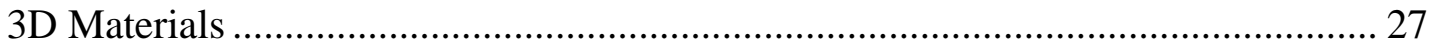

Microscale Double Cantilever Beam Specimens ……………………………….... 27

Microscale End Notch Flexure Specimens............................................................ 29

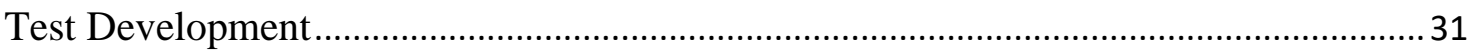

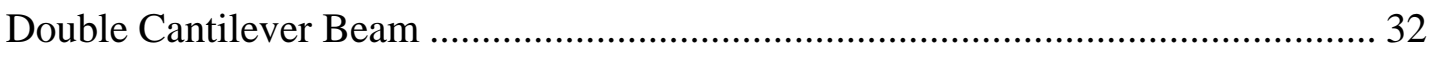

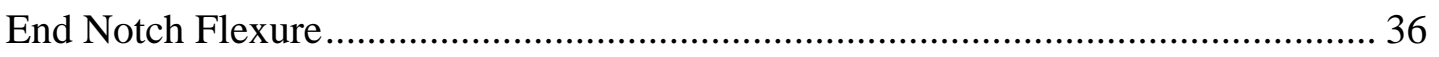

Adhesives and Adherends ......................................................................................... 38

CHAPTER IV - RESULTS AND ANALYSIS........................................................... 40

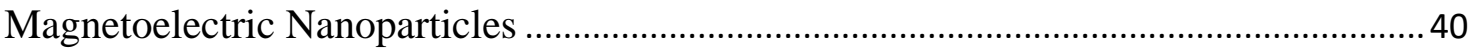

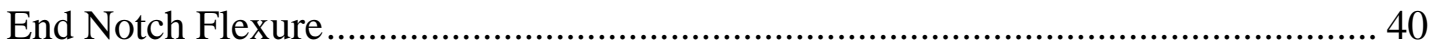

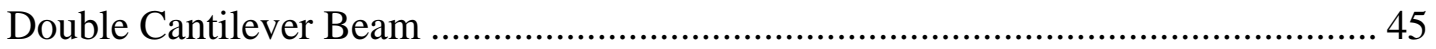

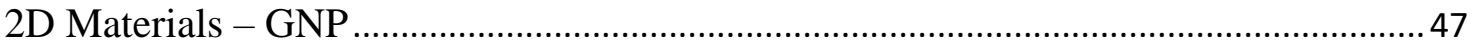

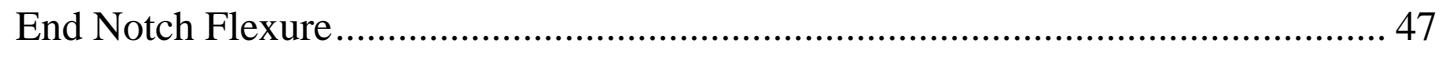

3D Materials - Graphene Foam............................................................................ 48 


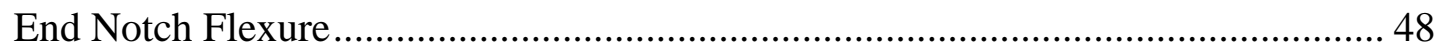

Double Cantilever Beam ................................................................................ 51

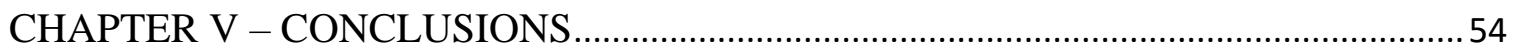

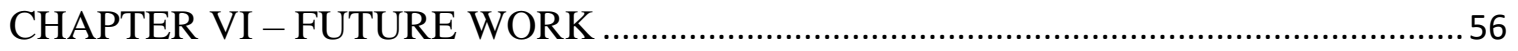

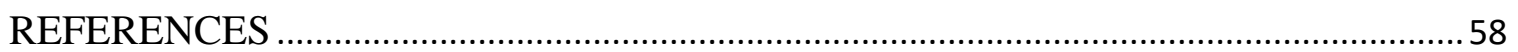




\section{LIST OF TABLES}

TABLE

PAGE

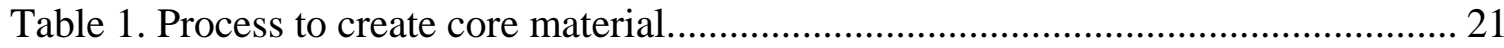

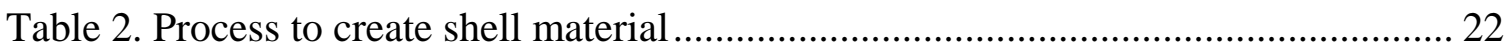

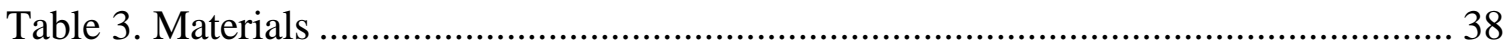

Table 4. Fracture toughness of undoped versus MENs doped adhesives....................... 44

Table 5. Fracture toughness of undoped versus GrF doped adhesives.......................... 49 


\section{LIST OF FIGURES}

FIGURE

PAGE

Figure 1. Stress state of bolted structural materials versus stress state of adhesively

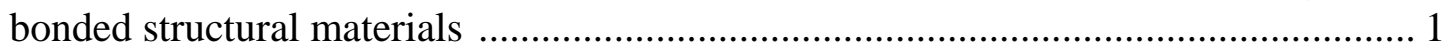

Figure 2. The fracture toughness loading mode......................................................... 3

Figure 3. Different types of adhesive fracture. ..................................................... 10

Figure 4. Double cantilever beam specimen ......................................................... 13

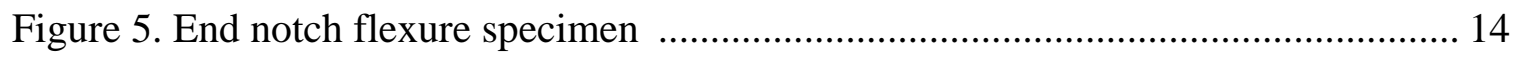

Figure 6. TEM image of a cobalt ferrite - barium titanate MEN ................................ 15

Figure 7. Representative image of graphene....................................................... 18

Figure 8. Low magnification SEM image of graphene foam ................................... 20

Figure 9. MENs Core Manufacturing process.................................................... 24

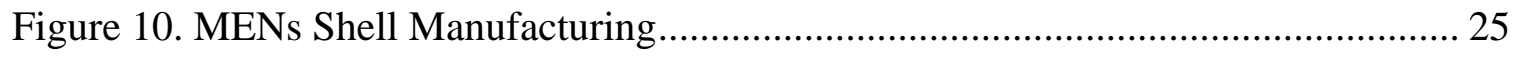

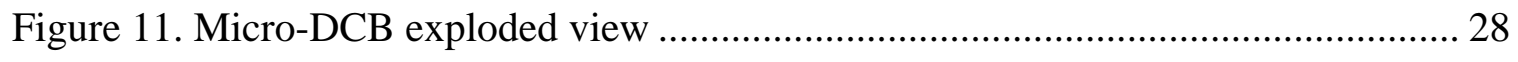

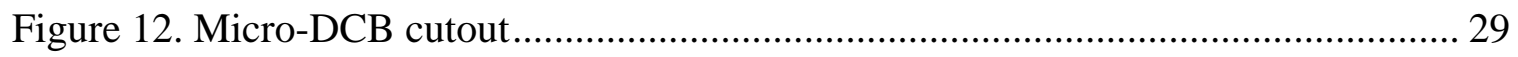

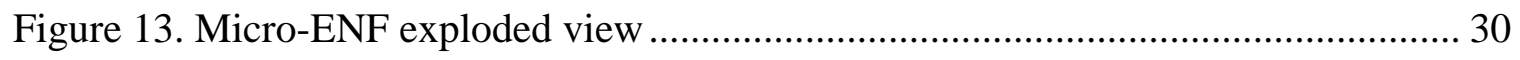

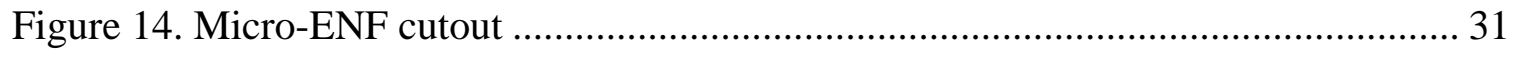

Figure 15. MTI Instruments SEM 1000 Tester................................................... 32

Figure 16. 3D printed fixtures attached to micro-DCB specimen. .............................. 34

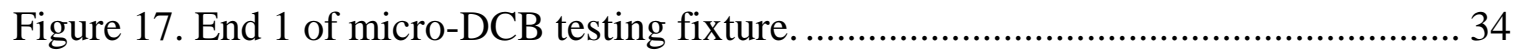

Figure 18. End 2 of micro-DCB testing fixture ................................................. 35

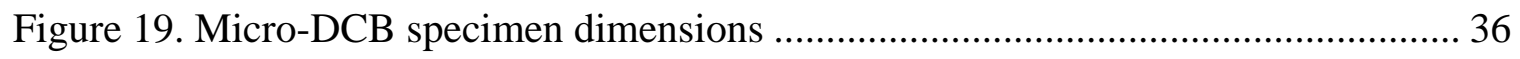

Figure 20. Micro-ENF fixtures configured in a three-point bend............................... 37

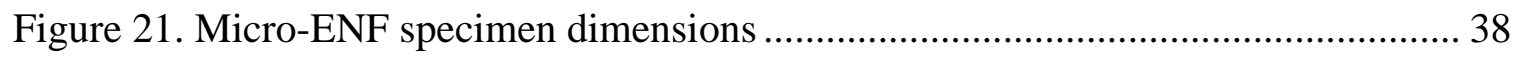


Figure 22. Load displacement curves for micro-ENF, undoped adhesive specimens..... 42

Figure 23. SEM images of interlaminar failure within the Adherend .......................... 42

Figure 24. Load displacement curves for micro-ENF, undoped adhesive specimens...... 43

Figure 25. Still images of the in situ loaded ENF specimen..................................... 43

Figure 26. GIIC values of undoped and MENs doped adhesives................................. 45

Figure 27. Load displacement curves for micro-DCB ........................................ 46

Figure 28. SEM still images of undoped micro-DCB sample .................................. 47

Figure 29. SEM images of MENs doped micro-DCB specimens ............................... 47

Figure 30. SEM still images of GNP doped adhesive micro-ENF test........................ 48

Figure 31. Load displacement curves for micro-ENF ….................................... 49

Figure 32. SEM images of adhesive sample ....................................................... 50

Figure 33. SEM images of GrF doped adhesive sample........................................ 51

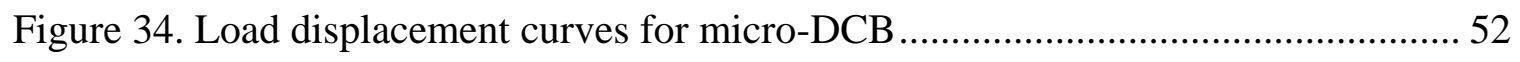

Figure 35. SEM still images of crack propagation during micro-DCB ....................... 53

Figure 36. SEM still images of crack propagation during micro-DCB testing of GrF

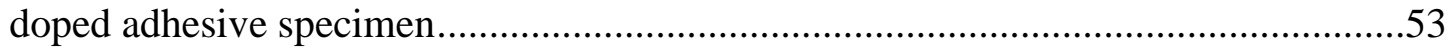




\section{CHAPTER I - INTRODUCTION}

Adhesive bonding of a variety of materials have been shown to have multiple advantages over traditional mechanical fasteners such as rivets and bolts. The use of mechanical fasteners to join structural materials has been long studied and understood. Mechanical fasteners can create robust joints as well as a known failure path. However, there are multiple disadvantages of using mechanical fasteners. Mechanical fasteners are typically made from high-density metals significantly increasing the weight of the structure [1]. Mechanical fasteners also require application points where holes are drilled in the structural materials to join the mechanical fasteners on either side which can lead to an excess of stress concentrations [2]. Adhesive bonding of structural materials could be used to vastly reduce these issues associated with mechanical fasteners, improving overall efficiency of structures by reducing their weight as well as simplifying the designs. Adhesive bonding can also create a more uniform stress state compared to mechanical fasteners (Fig. 1) [3].

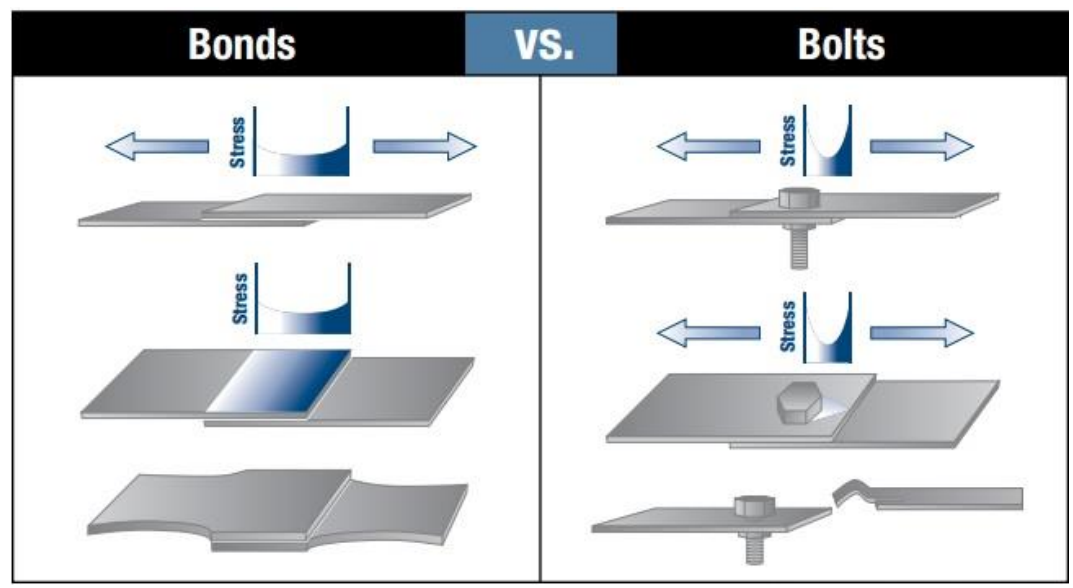

Figure 1. Stress state of bolted structural materials versus stress state of adhesively bonded structural materials (https://sehrainder.wordpress.com/2013/04/01/bond-adhesive-bond-d/)

Although there is a vast potential in the use of adhesive bonding on structural materials, there must be a better understanding of the fracture of adhesives. Currently, there 
is an inability and uncertainty in determining a health of an adhesive bond over its lifetime. This is a problem because it has been shown that environmental exposure, surface contamination, and mechanical fatigue can all effect the health of an adhesive bond [4]. Additionally, adhesive bonds cannot act to compartmentalizing fracture or damage which will could lead to catastrophic failure. Therefore, for adhesive bonding to be widely accepted, there must be a better understanding of the fracture mechanism of adhesives.

\section{$\underline{\text { Motivation }}$}

Adhesive bonding has been shown to successfully address some of the main problems with traditional fasteners, such as the reduction of the overall weight and a more uniformly distributed stress state. Although adhesive bonding has been shown as a possible improvement to bolts and rivets, the implementation on structural components have been complicated because of the limited knowledge of the fracture of adhesives. Typically, strict standards and regulations for adhesive bonds require a guarantee of every bond's integrity for any bonded structures [5], which leads to the stigma of adhesive bonds being considered inferior to mechanical fastened structures. Therefore, to increase the use of adhesives as a structural bonding agent and to improve the understanding of how cracks behave in an adhesive bond, microscale fracture toughness tests can be developed that will allow for real-time imaging of the crack propagation.

Although there are a variety of tests that determine the fracture toughness of a material, there is no tests that allow for high-magnification, real-time imaging of the crack propagation. Typically, fracture toughness testing is performed on a macroscale, where large specimens are fractured on universal tensile testing machines. Traditional fracture occurs in one of three different loading modes; Mode I, Mode II, and Mode III. Mode I 
fracture involves the opening of a pre-crack under a tensile load, which is commonly known as the opening mode. Mode II fracture involves the shearing of a pre-crack in-plane, which is known as the sliding mode. Finally, Mode III is the shearing of a pre-crack outof-plane, also known as tearing mode (seen in Fig. 2) [6].
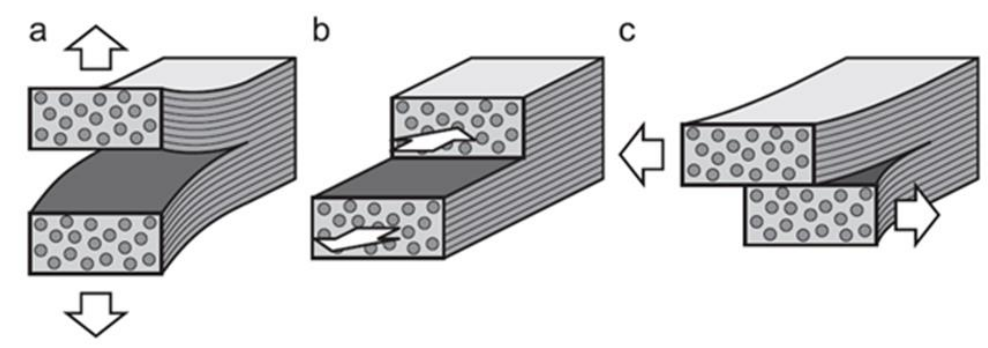

Figure 2. The fracture toughness loading mode; a) Mode I - Opening Mode, b) Mode II - Sliding Mode, \& c) Mode III - Tearing Mode

Currently, there is no fracture mode test that is commonly performed in situ, within the chamber of a scanning electron microscope (SEM), which will allow for real-time imaging of crack propagation. The ability to monitor the crack propagation under high levels of magnification simultaneously with the load and displacement graph would allow for a better understanding of the fracture of adhesives and will lead to the acceptance of adhesive bonding as a viable structurally bonding method.

\section{$\underline{\text { Research Objectives }}$}

The overall objective of the proposed research is to create novel, microscale fracture toughness testing to be using for in situ fracture testing for adhesives. These tests will allow for typical testing techniques to be performed in situ, within the chamber of a scanning electron microscope (SEM), to obtain real time analysis of the fracture of adhesives on a constituent scale. The objective of this project will be achieved will be completed by following two main groups of tasks: 
Task 1: Microscale fracture toughness testing development, which includes

a) Mode I and Mode II fracture test development for in situ testing.

b) Design and manufacturing of testing fixtures.

c) Developmental process to manufacture test specimens.

d) Optimizing test specimen geometry to ensure crack propagation.

Task 2: Utilize the developed test procedures to observe different reinforced adhesives in situ, which includes,

a) One-dimensional nanoparticle reinforcing agents - Magnetoelectric nanoparticles (MENs)

b) Two-dimensional reinforcing agent - Graphene Nanoplatelets (GNP)

c) Three-dimensional reinforcing agent-Graphene Foam (GrF)

The focus of this thesis is to take test procedures that are currently standardized on the macroscale and develop these tests into microscale versions. Although there are the three different types of loading modes in fracture mechanics, it is only feasible to perform mode I and mode II within the SEM chamber. One tests will be developed for mode I fracture; a microscale double cantilever beam (DCB) test. This will allow for the real-time imaging of the opening of a pre-crack in an adhesive bond. Mode II fracture will be investigated through a microscale, end notch flexure (ENF) test, which will be a microscale, three-point bend test. The first goal of this thesis will be broken down into two specific tasks. The first task will be to develop specimen holders that will be used with the in-situ tester. The in-situ tester that will be used as a testing platform will be the MTI SEM tester. The second portion of the first goal is to developed a process to manufacture the test specimens consistently. Finally, the test specimens were optimized for each test. This will 
include the pre-crack length, the bond line thickness, the adherend (the material being bonded) thickness, length, and width.

The second main goal of the thesis is to perform these test procedures for different adhesives and reinforced adhesives. There has been a large amount of research performed showing that adhesive properties can be improved using different particle reinforcing agents $[7,8,9]$. Although research has been done for particle reinforced adhesives, there has been no research done on the behavior of the crack propagation in these reinforced adhesives. Three different adhesive cases will be tested using different types of reinforcing agents as well as three different types of adhesives. The first type of reinforcing agent will be for a standard nanoparticle reinforcing agent. This nanoparticle reinforcing agent will be magneto-electric nanoparticles (MENs). The adhesive will be tested using the two different testing methods and compared to the results from just adhesive samples. The second task will be to test an adhesive doped with a two-dimensional material, or a single layer material. The two-dimensional material to be used will be graphene nanoplatelets (GNP). Finally, the tests will be done for a three-dimensional reinforcing agent, which will be graphene foam. Along with different reinforcing agents, the adhesives will be varied for each type of reinforcing agent to be used to ensure that the test procedures work for varying strengths of adhesives. 


\section{CHAPTER II - LITERATURE REVIEW}

\section{$\underline{\text { Review of Fracture Mechanics }}$}

Fracture mechanics is the study of material failures due to the propagation of cracks in a material caused by some applied load. The term fracture refers to the separation of a material into separate pieces due to the formation and propagation of a crack and a material's fracture toughness is the ability to resist fracture. The basics of linear elastic fracture mechanics (LEFM) began with Griffith in 1921 when he began to investigate why there was a vast difference between the theoretical stress needed to break atomic bonds of glass and the actual stress needed to fracture the glass. In the past, the general theory of elasticity was used to predict failure in crack-free (idealized) materials, but frequently this theory did not hold up to experimental values. Griffin correlated the fracture toughness of a material $\left(\mathrm{G}_{\mathrm{c}}\right)$, the critical value of strain energy release rate, to the plane stress in a material, the Young's modulus, and the crack length using Eq. 1 [10]. Griffith also found that the stress and half crack length (a) remained constant for multiple tests leading to the parameter, stress intensity factor $\left(K_{I}\right)$, which can be calculated using Eq. 2 [11].

$$
\begin{aligned}
\sigma_{f} & =\sqrt{\frac{G_{C} E}{\pi a}} \\
K_{I} & =\sigma \sqrt{\pi a}
\end{aligned}
$$

Although Griffith laid the ground work for the field of fracture mechanics, the true "father of fracture mechanics" is George Irwin. George Irwin expanded on previous work of Griffith, Inglis [12], and Westergaard [13]. Irwin noticed that Griffith's theory worked excellently for brittle materials but proved to provide poor predictions for ductile materials. Irwin discovered that in ductile materials, the occurrence of plastic deformation effects the 
fracture behavior. Near the crack tip, a plastic zone develops that increases in size as the load increases which leads to the dissipation of energy. Irwin developed a modified version of Griffith's equation including the plastic dissipation $\left(G_{P}\right)$ seen in Eq. 3 and Eq. 4 $[14,15,16]$. Irwin breaks down the energy into two separate parts, the stored elastic strain energy $(\gamma)$ and the dissipated energy. Griffith's method worked for brittle materials because the stored elastic strain energy dominates the overall energy whereas in ductile materials, the plastic dissipation term dominates.

$$
\begin{aligned}
& \sigma_{f} \sqrt{a}=\sqrt{\frac{E G}{\pi}} \\
& G=2 \gamma+G_{P}
\end{aligned}
$$

Linear elastic fracture mechanics (LEFM) works very well in problems in which the plastic zone surrounding the crack tip is small when compared to the crack size. In materials involving large loads, the plastic zone around the crack may be larger than the crack itself. Most engineering materials exhibit nonlinear elastic and inelastic behavior under these circumstances and linear elastic fracture mechanics models will not be satisfactory for these circumstances. A new model needed to be developed to account for this behavior, therefore elastic-plastic fracture mechanics was developed. Wells first discovered the shortcomings of the linear elastic fracture mechanics models while attempting to measure fracture toughness of structural steels. He observed that the plastic deformation of the crack faces prior to fracture was causing the decrease in sharpness of the crack tip. Wells could correlate the fracture toughness was proportional to the degree of crack blunting [17,18]. This became known as the crack tip opening displacement (CTOD). The next development of elastic-plastic fracture mechanics came with Rice in the 
late 1960s. This fracture toughness parameter became known as the J-integral. Rice assumed an area ahead of the crack tip that has non-linear elastic deformation. This deformation area can be assumed to be an accurate representation of the material's load response. This failure parameter is denoted as $\mathrm{J}$ and can be calculated using Eq. 5 and Eq. 6. This parameter can be related the stress intensity factor through Eq. 7 , where $\mathrm{E}^{*}$ is calculated by Eq. 8 for plane stress and Eq. 9 for plane strain [19].

$$
\begin{aligned}
& J=\int_{\Gamma}\left(w d y-T_{i} \frac{d u_{i}}{d x} d s\right) \\
& w=\int_{0}^{\varepsilon_{i j}} \sigma_{i j} d \varepsilon_{i j} \\
& K=\sqrt{E^{*} J} \\
& E^{*}=E \\
& E^{*}=\frac{E}{1-v^{2}}
\end{aligned}
$$

As previously discussed, there is three linearly independent modes to create a propagation of a pre-crack; mode I, mode II, and mode III. The different modes represent the directionality of the stresses acting on the crack rather than the actual behavior of the crack. The first mode, known as opening mode, consists of an applied tensile load in the normal direction of the crack plane. This will cause the material to open, effectively propagating the crack (Fig. 2a). Mode II is known as the sliding mode (Fig. 2b). This mode consists of an in-plane shear stress. The final mode, mode III, is known as the tearing mode and consists of an out-of-plane shear stress (Fig. 2c). Each mode of testing fracture toughness has specific testing procedures that allow for the calculation of different fracture toughness values; GIC, GIIC, and GIIIC, respectively. The Gc values can be calculated 
depending on which test procedure being used. Typically, for different testing modes, the stress intensity factors are considered by the stress distribution near the crack tip (in polar coordinates). Each testing mode has general equations that can be defined by Eq. 5, Eq. 6 , and Eq. 7 [20].

$$
\begin{aligned}
& K_{I}=\lim _{r \rightarrow 0} \sqrt{2 \pi r} \sigma_{y y}(r, 0) \\
& K_{I I}=\lim _{r \rightarrow 0} \sqrt{2 \pi r} \sigma_{y x}(r, 0) \\
& K_{I I I}=\lim _{r \rightarrow 0} \sqrt{2 \pi r} \sigma_{y z}(r, 0)
\end{aligned}
$$

Fracture mechanics can be used in adhesive bonding to determine the fracture toughness of an adhesive material. Williams had begun investigating the fracture of two different materials at the bonded interface (adhesive fracture) [21] based off previous work from Dannenburg [22], and Malyshev and Salganik [23]. The fracture of adhesive typically occurs in one of three major types of fracture; cohesive fracture, adhesive fracture, and adherend fracture. The different types of adhesive fracture can be seen in Fig. 3 as well as the mixed modes of fracture. Cohesive fracture is the ideal fracture type for testing adhesive fracture. The cohesive fracture occurs when the crack propagates through the bulk of the adhesive. The crack will not propagate to the adherend (bonded material) and will remain in the adhesive throughout the entire specimen. When cohesive fracture occurs, the calculated fracture toughness can be considered the fracture toughness values for the bulk adhesive [24]. Adhesive fracture occurs when the crack propagates to the adherend instead of through the adhesive. This fracture will cause a de-bonding of the adhesive and the adherend which will allow for calculations of the adhesive fracture toughness [25]. The adhesive fracture toughness values will generally be much smaller than the values of 
fracture toughness for the bulk adhesive. Adherend fracture occurs when the adherend is much weaker than the adhesive. This is when the crack propagates to the interface of the adhesive and the adherend and continues propagation through the adherend. Typically, this occurs in composite materials [26]. Fracture can also occur in a combination of the cohesive, adhesive, and adherend fracture. Generally, when this occurs, the crack will propagate through the adhesive towards the interface and then may jump to the other interface and continue this process. This type of fracture occurs when there are pre-stresses within the material, surface contamination prior to bonding, or an incomplete curing of the adhesive in some portions [27].
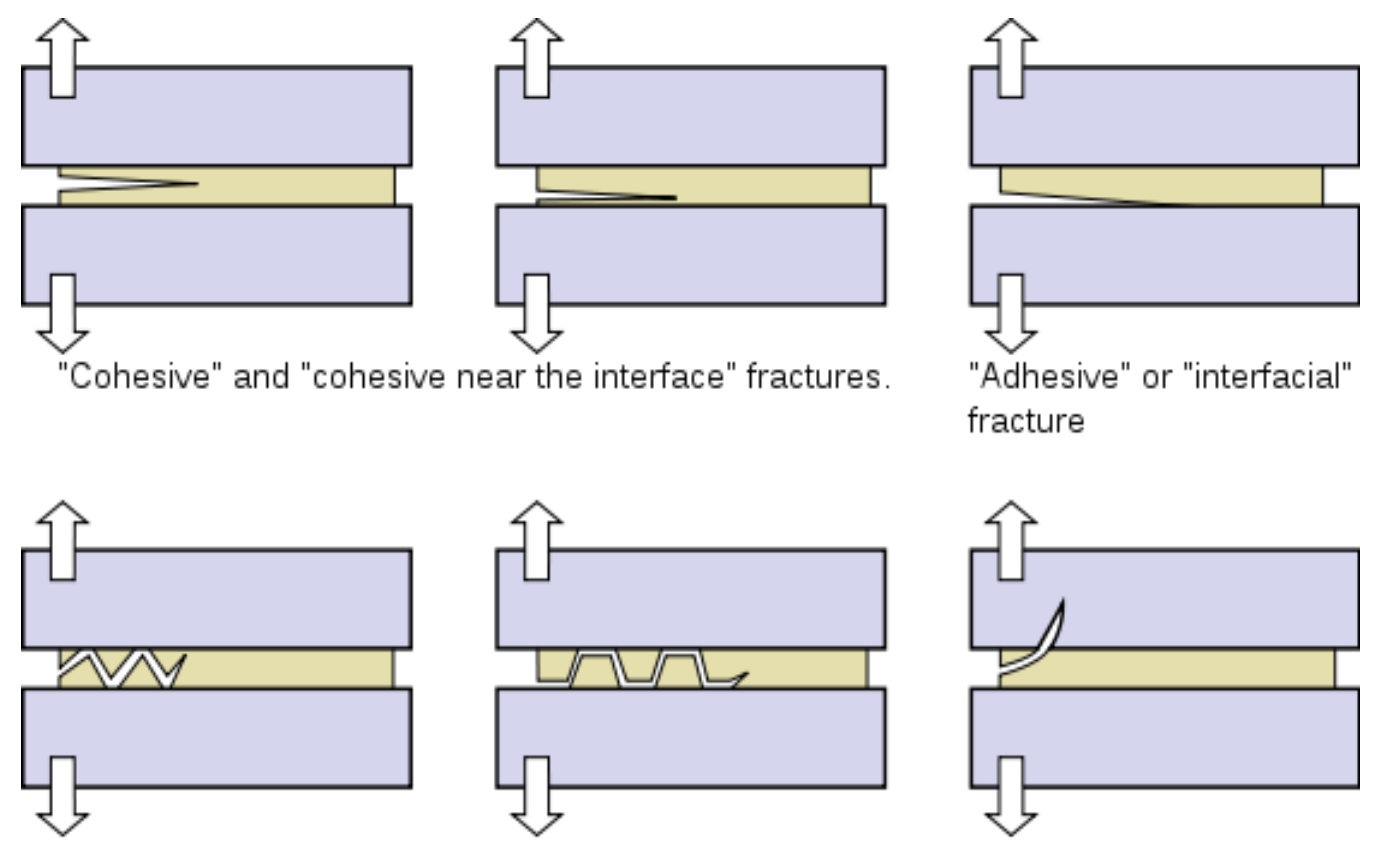

Fracture jumping from one interface to the other.

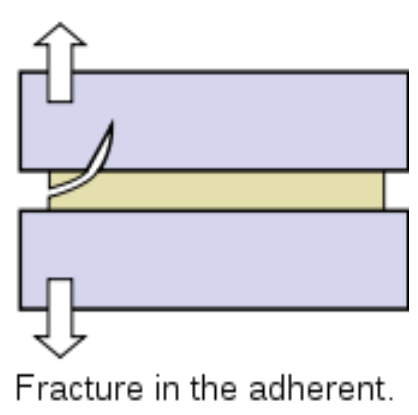

Figure 3. Different types of adhesive fracture; Cohesive fracture, Adhesive fracture, Fracture jumping interfaces, and Adherend fracture.

The current method to determine which type of fracture occurs within an adhesive specimen is a post-test observation of the specimen. The analysis of the different fracture types occur post-test because it is very difficult to see the crack propagation on a 
macroscale with low magnification imaging. The crack propagation also typically occurs at a relatively high speed, so it is difficult to capture the propagation. Current methods require an observation of the two sides of the fractured specimen. Cohesive fracture is determined to take place when both sides of the fractured specimen have a layer of remaining adhesive. Adhesive fracture is considered to have taken place when one side of the specimen has a layer of adhesive and one side of the specimen is just the adherend. The mixed mode of the fracture can be determined by the variation of the thickness of the remaining adhesive layer as well as portions of purely adherend.

\section{$\underline{\text { Adhesives }}$}

Adhesives as a general term, refers to the ability of a material to bond two surfaces together and subsequently resisting their separation. The broad term of adhesives encompasses the commonly known adhesive types such as glues, cements, epoxies, and mortars. The materials being bonded are typically referred to as substrates or adherends. Some of the earliest uses of adhesives were Babylonian's use of Bituminous cements 6000 years ago [28], to the Roman's use sealants for their ships [29]. These types of early, historical adhesives were natural adhesives, whereas more modern adhesives are synthetic. The first modern glue was developed in Holland in the late 1600s [30] and continued developing in Germany, Switzerland, and the United States in the early nineteenth century. During the 1920 s to the 1940 s, adhesive development took a great leap forward due to the advances in new plastics and resins. Adhesives such as poly (vinyl acetate), commonly known as wood glue or PVA glue, acrylic polymer adhesives, and epoxies were all developed during World War II $[31,32,33]$. Recently, the advancement of the adhesive 
industry has been driven by the aircraft and aerospace industries with the factor of weight being vital in aerospace design [34].

There are multiple theories of adhesion that attempt to successful explain the adhesion phenomenon. The mechanical interlocking theory says that adhesion occurs due to porous or rough surfaces that allow for the adhesive to flow into the adherend. The adhesive interlocks with the adherend effectively acting as the adhesion strength [35]. The molecular diffusion theory offers a suggested approach for explaining polymer to polymer adhesion. This adhesion is created by a diffusion of polymer molecules across the interface $[36,37,38]$. The electronic theory considers the electrostatic forces between the adherend and the adhesive affect the adhesive strength significantly [39]. Although, these theories are some of the prevalent theories on adhesive strength, they are no considered to be completely accepted as accurate.

\section{Double Cantilever Beam}

One of the most common ways to study fracture mechanics of mode I failure (opening mode) is the double cantilever beam (DCB) test (Fig. 4). The double cantilever beam test was a technique in which both sides of the specimen were considered as a cantilever beam. This method was first used by Benbow and Roesler [40]. Subsequent additions and refinements to the DCB test was made by Gillis and Wierderhorn [41,42]. The use of the double cantilever beam test for measureing the fracture toughness of adhesives after the work of Mostovoy and Ripling [43]. Currently, the double cantilever beam tests have been standardized by ASTM international [44]. The DCB tests involves the applied load using end blocks or hinges to open the pre-crack normal to the crack plane. The tests are done using displacement control recording the load and the propagated crack 
length. These standardized tests are macroscale with dimensions of $125 \mathrm{~mm}$ long and 20 to $25 \mathrm{~mm}$ wide. The substrate thickness is to be 3 to $5 \mathrm{~mm}$ thick with the initial crack length of $50 \mathrm{~mm}$. Eq. 13 can be used to calculate the mode I fracture toughness using the Modified Beam Theory (MBT) method [45].

$$
G_{1}=\frac{3 P \delta}{2 b a}
$$

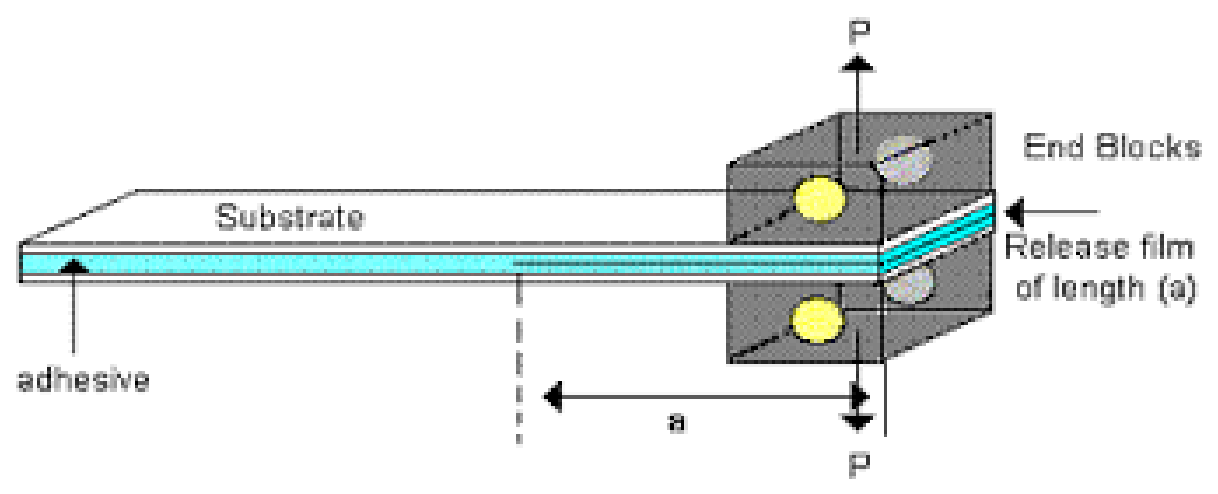

Figure 4. Double cantilever beam specimen. (ref)

\section{End Notch Flexure}

End notch flexure (ENF) testing is one of the most common methods in determining mode II fracture toughness. The end notch flexure test is more commonly known as a fourpoint or a three-point bend test (Fig. 5). It consists of a rectangular specimen that is loaded between either three or four points of contact and the load is applied in a displacement control mode. The ENF specimen must be greater than $160 \mathrm{~mm}$ long and 19 to $26 \mathrm{~mm}$ wide. The thickness of the specimen must be 3.4 to $4.7 \mathrm{~mm}$ with a minimum pre-crack of $40 \mathrm{~mm}$. The dimensions and loading rates can be found in the ASTM standards [46]. 


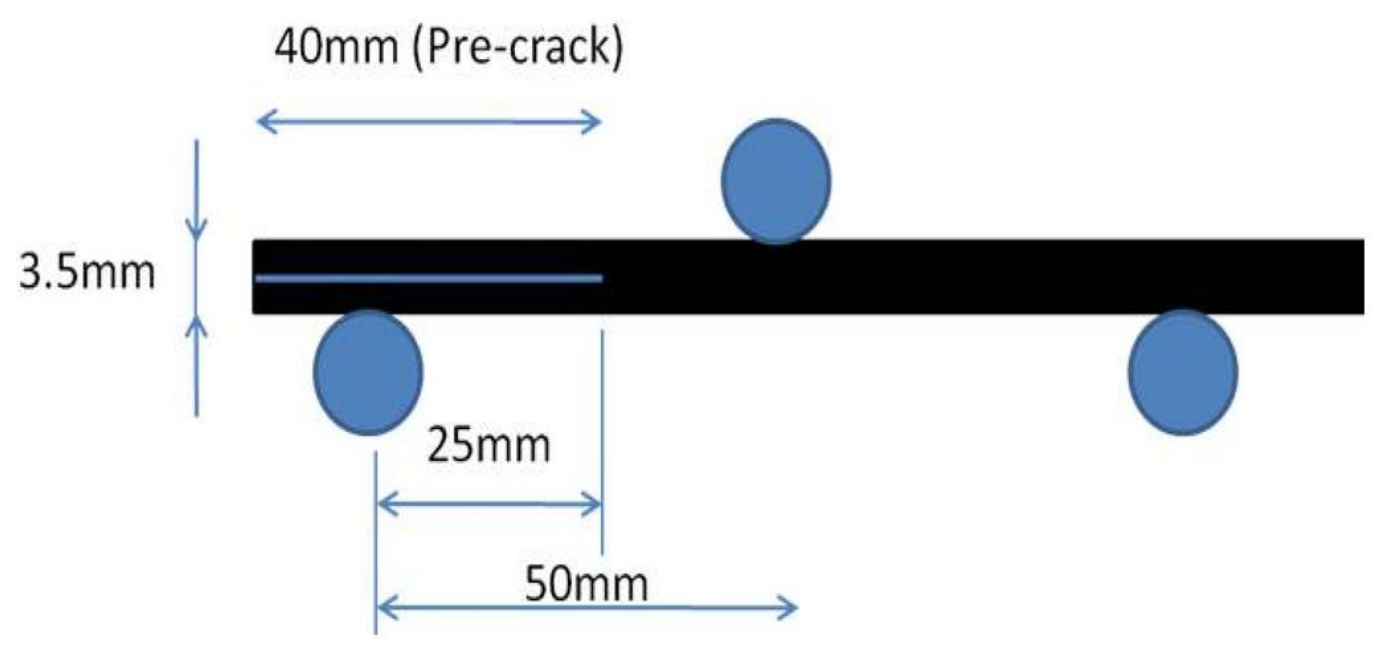

Figure 5. End notch flexure specimen (ref)

The end notch flexure test will allow for the calculation of the mode II fracture toughness. The actual toughness is calculated for pre-cracked specimens by using Eq. 14 which uses the maximum load, the location of the roller at the pre-cracked end, and the area's specimen.

$$
G_{I I C}=\frac{3 m P_{\max }{ }^{2} a_{p c^{2}}}{2 B}
$$

\section{$\underline{\text { Adhesive Reinforcing Agents }}$}

\section{Magneto-Electric Nanoparticles}

The magneto-electric nanoparticles (seen in Fig. 6) are unique nanoparticles that capitalize on the magneto-electric effect. This effect is a coupling of the two different field effects, magnetostriction and piezoelectricity. The coupling is typically achieved through lattice matching of two different nanostructures. Thus, the MENs show an electric polarization due to the application of a magnetic field as well as a magnetic polarization due to the application of an electric field. 


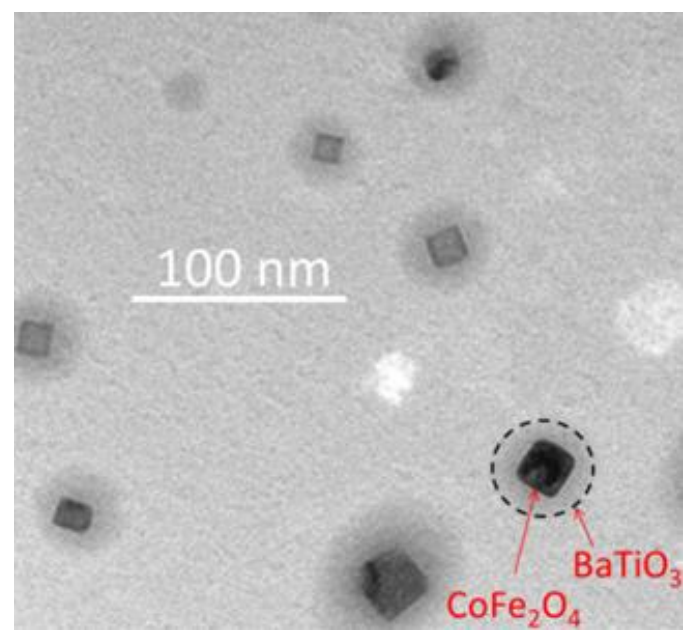

Figure 6. TEM image of a cobalt ferrite - barium titanate MEN (ref)

To a first-degree approximation, the magneto-electric effect can be determined by Eq. 15 where $\Delta \mathrm{P}$ is the electric polarization, the $\mathrm{H}$ is the induced, or applied, magnetic field, and the $\alpha$ is the magneto-electric coefficient. The magneto-electric coefficient is the coefficient that relates the magnetic field to the electric polarization. The dipole surface charge density, the amount of charge per unit of surface area, can be evaluated using Eq. 16 where $\mathrm{d}$ is the diameter of the MENs, and the $\mathrm{Q}$ is the charge. Therefore, any change in the electric dipole change will induce an electric field, which in turn, due to the magnetoelectric effect, will result in a change of the magnetization (Eq. 17), which can be detected via magnetometry techniques.

$$
\begin{aligned}
& \Delta P=\alpha H \\
& \sigma_{M E} \approx \frac{Q}{\pi d^{2}} \\
& \Delta M=\alpha \sigma_{M E}=\frac{\alpha Q}{\pi d^{2}}
\end{aligned}
$$

This phenomenon will allow for the change in the magnetic moment due to the changing surroundings of the MENs to be measured which will ultimately correlate to the 
health of the bond [47]. These changes are easily measured using a magnetometer such as a vibrating sample magnetometer (VSM), alternating field gradient magnetometer (AGM), nuclear magnetic resonance (NMR), BH looper, or another magnetometer.

The magneto-electric nanoparticles are a core-shell nanoparticle that consists of different materials for the core and shell. The core of the MENs consists of cobalt ferrite $\left(\mathrm{CoFe}_{2} \mathrm{O}_{4}\right)$, which is a ferromagnetic system with a relatively strong magnetostrictive effect, while the shell consists of barium titanate $\left(\mathrm{BaTiO}_{3}\right)$, which is a popular piezoelectric structure. The core is created by a solution of cobalt (III) nitrate hexahydrate $\left(\mathrm{Co}\left(\mathrm{NO}_{3}\right)_{3} \bullet 6 \mathrm{H}_{2} \mathrm{O}\right)$ and iron (III) nitrate nonahydrate $\left(\mathrm{Fe}\left(\mathrm{NO}_{3}\right)_{3} \bullet 9 \mathrm{H}_{2} \mathrm{O}\right)$. This solution is heated to $120{ }^{\circ} \mathrm{C}$ while adding polyvinylpyrrolidone and sodium borohydride $\left(\mathrm{NaBH}_{4}\right)$. This process creates the cobalt ferrite nanoparticles. The next step is to create the barium titanate shell $\left(\mathrm{BaTiO}_{3}\right)$. This is done by creating two separate solutions. The first solution is an aqueous solution of citric acid $\left(\mathrm{C}_{6} \mathrm{H}_{8} \mathrm{O}_{7}\right)$ and barium carbonate $\left(\mathrm{BaCO}_{3}\right)$. The second solution is an ethanolic solution of citric acid $\left(\mathrm{C}_{6} \mathrm{H}_{8} \mathrm{O}_{7}\right)$ and titanium (IV) isopropoxide $\left(\mathrm{C}_{12} \mathrm{H}_{28} \mathrm{O}_{4} \mathrm{Ti}\right)$. These two solutions are combined with the cobalt ferrite nanoparticles and heated at $70{ }^{\circ} \mathrm{C}$ for 12 hours while being stirred at 200 rotations per minute. This creates the precursor which is then heated to varying temperatures for 5 hours to create the MENs.

Magneto-electric nanoparticles have been receiving attention from researchers in the recent past especially in biomedical departments. The MENs exhibit a capability of interreacting with cells and viruses [48]. Most research involving magneto-electric nanoparticles have been in developing drug delivery systems where the functionalization of the MENs creates a targeted drug release system [49]. This method has been shown to work for ovarian cancer cells in a laboratory setting [50]. The possibility of using MENs 
as a reinforcing and activating agent in nanocomposites for shape memory polymers has also been investigated [51]. The MENs doped adhesive could provide the benefit of being a multifunctional adhesive. The doping of the MENs could provide a particle reinforcing agent as well as providing a non-invasive, structural health monitoring system. In previous studies, modeling and characterization has been done using similar nanoparticles as a toughening agent [52-55]. There is a well-known mechanism for nanoparticle reinforcing agents to change properties of polymers, however, there is no known mechanism of crack propagation. MENs specifically, in single-lap shear tests, have shown to increase the shear strength of an adhesive by $24 \%$ with the addition of small volume concentrations of MENs [56]. Along with strengthening of the adhesive, the MENs could serve as a tool for structural health monitoring. MENs doped adhesive has shown the sensibility to detect environmental exposure in an adhesive bond [57]. Initial results also indicate the potential of MENs doped adhesive to be able to detect mechanical damage in an adhesive bond due to changing magnetic signature.

\section{D - Graphene Nanoparticles}

Graphene nanoparticles (GNP) are nanoparticles made up of graphene, which is made up of one-atom thick layer of carbon. GNP typically consist of multiple graphene sheets. Since its recent discovery, graphene has been one of the largest areas of research in material sciences [58]. Graphene typically exhibits a larger lateral spread with a layer of graphene being about $0.3 \mathrm{~nm}$. Graphene has carbon atoms linked together by strong C-C$\sigma$ bonds creating a two-dimensional structural which result in a hexagonal lattice (Fig.7). 


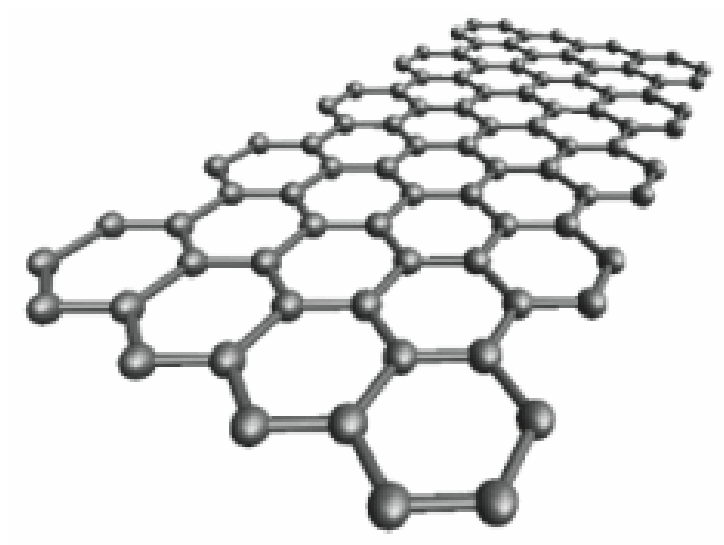

Figure 7. Representative image of graphene

Due to this strong two-dimensional network, graphene is one of the strongest known materials with a Young's modulus of $0.5-1 \mathrm{TPa}$ [59]. Graphene also shows excellent thermal conductivity, high surface area to mass ratio, and excellent conductor properties [60]. Because of the excellent properties of graphene materials, they have been used extensively in polymer composites, metals, and ceramics to enhance their performance. One problem that has been well known in the use of graphene as a nanoparticle filler is that graphene can be difficult to uniformly dispersed in a solution [61]. This is due to the large agglomerations due to high van der Waals forces. In order to counteract this, graphene oxide has been introduced as an alternative. Graphene nanoplatelets have been compared to carbon nanotubes in an epoxy matrix. Graphene nanoplatelets show an improvement in tensile strength, Young's modulus, and fracture toughness [62].

The difficulty of producing large amounts of defect-free graphene has been the limiting factor in large scale applications of graphene doped composites. Due to this, many production methods for graphene have been developed. One of the most common methods for producing graphene is through sonication. Graphite can be dispersed into a liquid 
medium for sonication which will create graphene. This method can be useful for the simplicity but can also limited amount of production due to the absence of prevention of the restacking of graphene sheets due to the van der Waals forces [63]. Another method is chemical vapor deposition (CVD). CVD uses epitaxial growth of graphene on substrates. This is done in two ways; the graphitization of $\mathrm{SiC}$ through high temperature $\left(1300^{\circ} \mathrm{C}\right)$ activation [64], and the decomposition of ethylene onto a ruthenium substrate [65].

\section{D - Graphene Foam}

Although graphene as a two-dimensional material has attracted various researches, graphene foam $(\mathrm{GrF})$ has obtained an uncanny amount of attention. Fig. 8 shows a low magnification SEM image of graphene foam. Graphene foam has shown a variety of potential improvements and excellent mechanical and electrical properties. Currently, graphene foam composites are being heavily investigated as an energy storage method [66], highly sensitive sensors [67], and various biomedical applications. Graphene foam forms a low density continuous network of graphene which due to its low density $\left(0,005 \mathrm{~g} / \mathrm{cm}^{3}\right)$ is an excellent, lightweight reinforcement [68]. Due to the structure of foam, the requirement of different dispersion methods is essentially obsolete. The unique properties

of graphene foam can be attributed to the weaker $\mathrm{sp}^{2}$ bonding between graphene layers and the porosity of the foam. This can lead to significant flexibility and strength. 3D graphene foam shows a potential in replacing mechanical fasteners or wire reinforcements in adhesive bonds. 


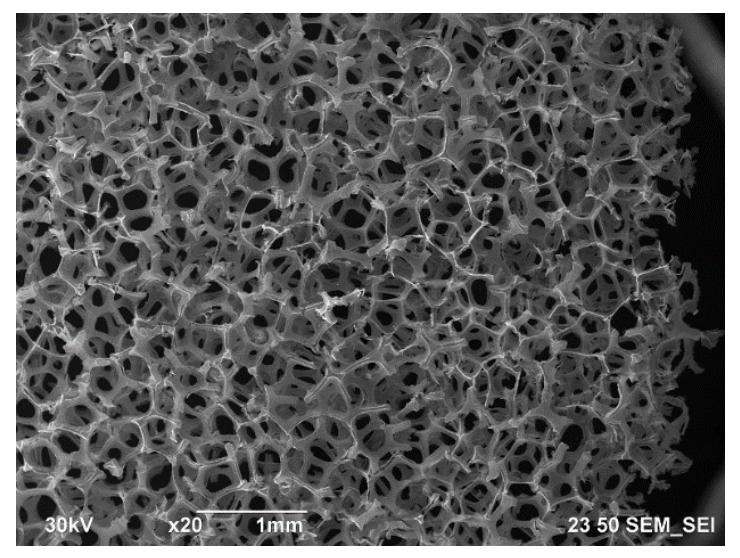

Figure 8. Low magnification SEM image of graphene foam ( GrF)

There have been some studies focusing on polymer composites reinforced with graphene foam. Most of these studies involving graphene foam reinforced composites investigate their potential as supercapacitors, conductors, and sensors. Zhao et al showed the potential for strong, flexible structures with a compressive strain up to $80 \%$ [69]. Graphene-PMMA (polymethylmethylacrylate) shows an increase in tensile toughness and ductility where the GrF-PMMA was a foam like composite structure [70]. However, none of the current studies on graphene foam reinforced composites focus on the mechanical and functional properties as components for adhesive bonding. 


\section{CHAPTER III - METHODOLOGY}

\section{$\underline{\text { Test Preparation }}$}

\section{Magneto-Electric Nanoparticles}

As discussed previously, the magneto-electric nanoparticles (MENs) are a coreshell material consisting of cobalt ferrite $\left(\mathrm{CoFe}_{2} \mathrm{O}_{4}\right)$ as the core material and barium titanate $\left(\mathrm{BaTiO}_{3}\right)$ as the shell material. The cobalt ferrite core is a ferromagnetic system with a relatively strong magnetostrictive effect and the barium titanate having a strong piezoelectric effect. The MENs can be easily made using basic chemistry knowledge to first create the core material, then using the cores creating the shell material. Fig. 9 and 10 and Tables 1 and 2 show the process to create the MENs.

Table 1. Process to create core material.

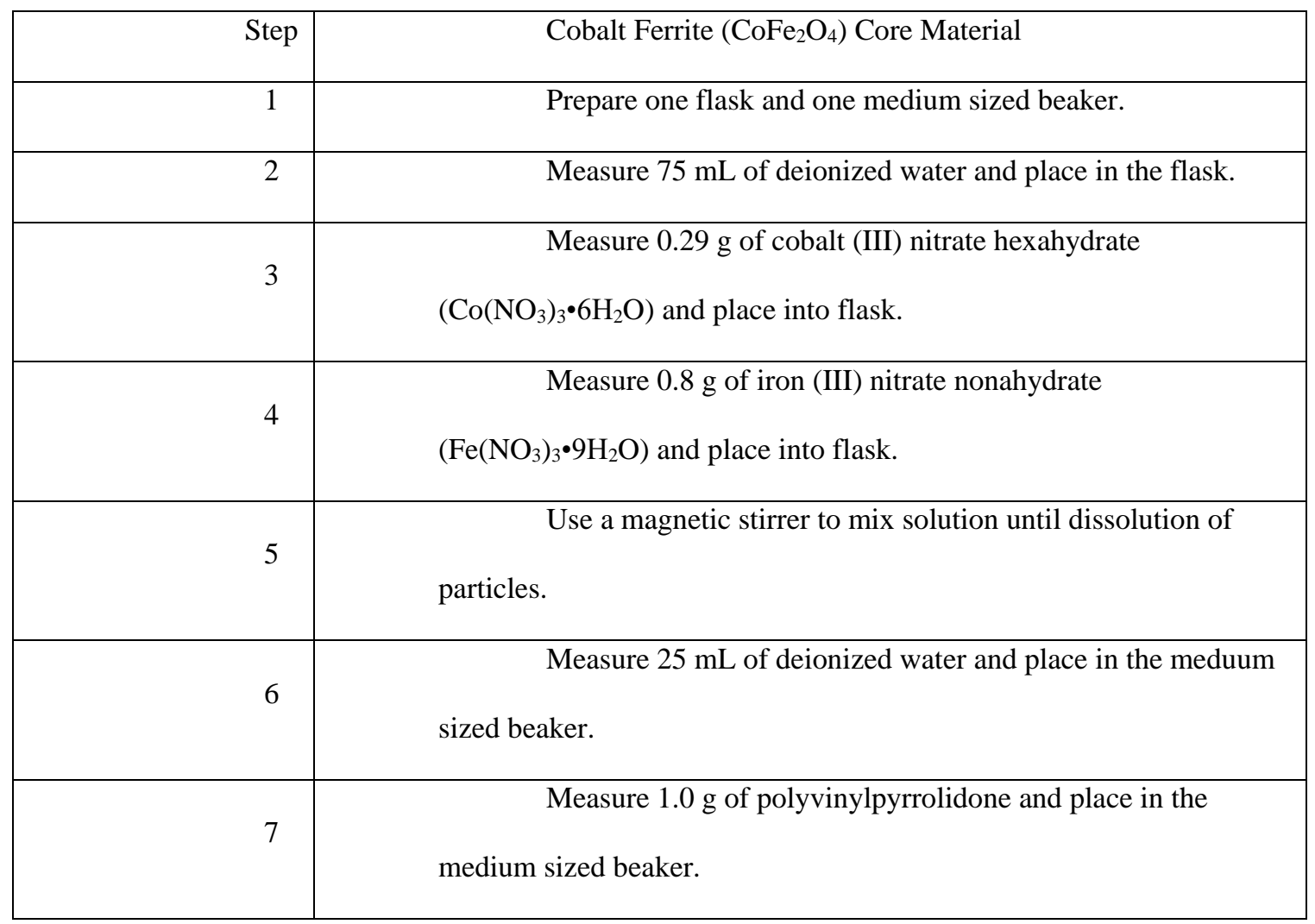




\begin{tabular}{|c|c|}
\hline 8 & $\begin{array}{c}\text { Measure } 4.5 \mathrm{~g} \text { of sodium borohydride }\left(\mathrm{NaBH}_{4}\right) \text { and place in } \\
\text { the medium sized beaker. }\end{array}$ \\
\hline 9 & Use a magnetic stirrer to mix solution until dissolution of \\
particles.
\end{tabular}

Table 2. Process to create shell material

\begin{tabular}{|c|c|}
\hline Step & Barium Titanate $\left(\mathrm{BaTiO}_{3}\right)$ Shell Material \\
\hline 1 & Prepare one $600 \mathrm{~mL}$ beaker (Beaker 1) and one $250 \mathrm{~mL}$ \\
\hline 2 & Meaker (Beaker 2). \\
\hline 3 & Measure $5 \mathrm{~g}$ of citric acid and add to beaker 1. \\
\hline 4 & Magnetically stir beaker 1 until citric acid is completely \\
\hline 5 & dissolved. \\
\hline 6 & Measure $240 \mu \mathrm{L}$ of titanium iv isopropoxide and add to \\
\hline 7 & beaker 1. \\
\hline 8 & Magnetically stir beaker 1 for 2 - 5 minutes until completely \\
\hline 9 & Measure $150 \mathrm{~mL}$ of deionized water and add to beaker 2. \\
\hline
\end{tabular}




\begin{tabular}{|r|r|}
\hline 10 & $\begin{array}{l}\text { Magnetically stir beaker 2 for 3 - 5 minutes until completely } \\
\text { dissolved. }\end{array}$ \\
\hline 11 & Pour beaker 2 into beaker 1 and magnetically stir 3 - 5 \\
minutes.
\end{tabular}




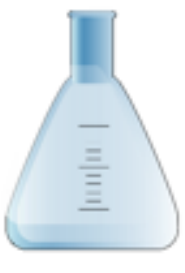

Solution 1:

$75 \mathrm{~mL}$ D.I. Water
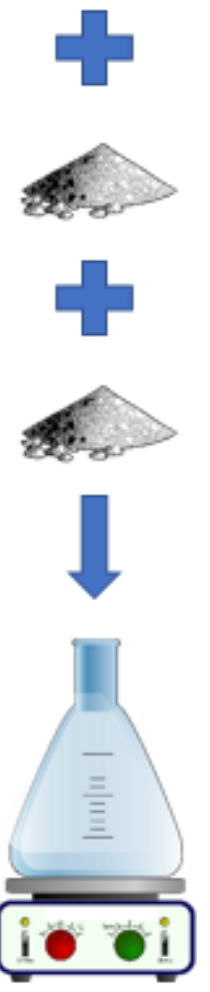

$0.8 \mathrm{~g}$ $\mathrm{Fe}\left(\mathrm{NO}_{3}\right)_{3} \cdot 9 \mathrm{H}_{2} \mathrm{O}$

Magnetically Stir for 3-5 Minutes

Heat to $70^{\circ}$ $\mathrm{C}$ at $300 \mathrm{rpm}$

$\mathrm{Co}\left(\mathrm{NO}_{3}\right)_{3} \cdot 6 \mathrm{H}_{2} \mathrm{O}$
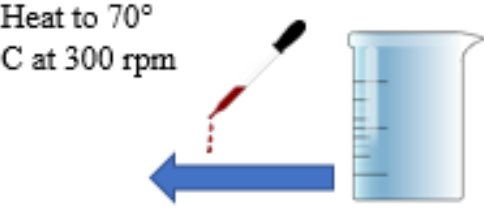

Solution 2:

$25 \mathrm{~mL}$ D.I. Water
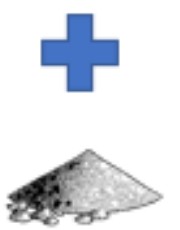

$1.0 \mathrm{~g}$

Polyvinylpyrrolidone
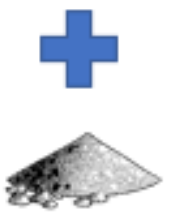

$4.5 \mathrm{~g} \mathrm{NaBH}_{4}$

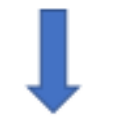

Magnetically Stir for 3-5 Minutes

Drop Solution 2 into 1, a few drops at a time.

\section{Final Solution:}

Once completely mixed, raise to $100^{\circ} \mathrm{C}$ and hold for 12 hours.

Figure 9. MENs Core Manufacturing process. 


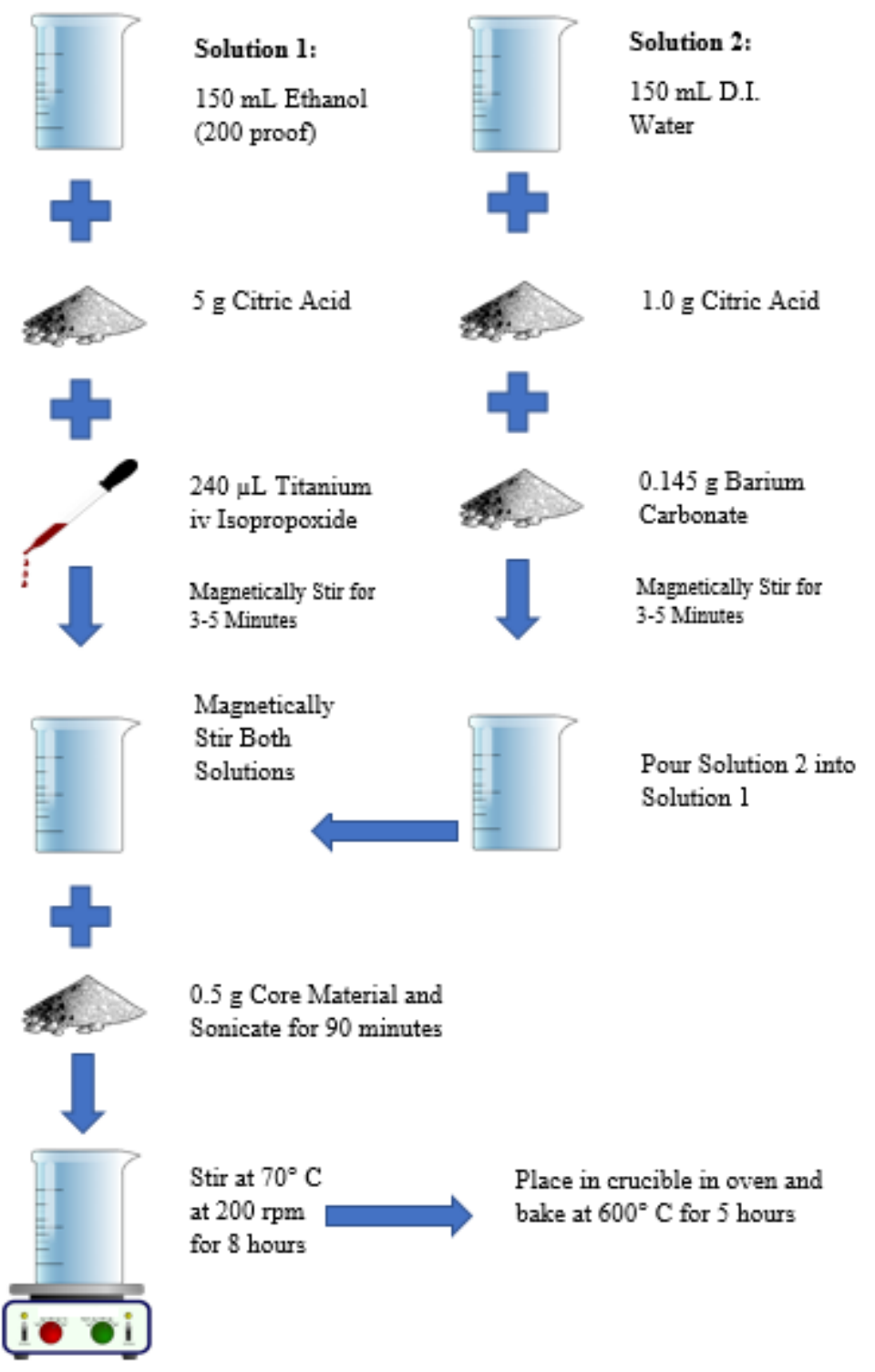

Figure 10. MENs Shell Manufacturing

For the MENs doped adhesive, the 3M Scotch-Weld Two-Part Epoxy EC-2615 was used for the adhesive. To disperse the MENs into the adhesive, hand mixing was used. Although there are more consistent methods to disperse particles into a matrix, hand mixing was the only viable option for this specific adhesive due to the high viscosity. The MENs were doped at a 5\% vol. concentration into the adhesive. The MENs were measured out 
and then dispersed into the hardener part of the epoxy. The hardener was then mixed into the base of the epoxy and the epoxy then used to depend on which test specimen was created.

\section{D Materials}

The 2D GNP that was used for this thesis was purchased in powder form. The GNP (xGNP-M-5) were purchased from XG Sciences in Lansing, MI, USA. This GNP typically exhibits large amounts of agglomerations due to the high surface energy and van der Waals forces. In order to counteract this, the agglomerations must be broken up. To do this, the powder is dispersed into a medium and tip sonicated. The GNP must be used relatively quickly after tip sonication because the GNP will quickly begin to agglomerate back due to the van der Waals forces. As well as agglomerating, the sonicated GNP will begin to oxidize as well. Therefore, it is important to ensure the GNP will be used in a quick manner. The medium that is used to tip sonicate can be acetone due to it having no known reactions to the GNP [68].

For the GNP doped adhesive, the Applied Poleramic SC-15 was used for the adhesive. The GNP, as previously discussed, is difficult to uniformly disperse. The MENs were doped at a 5\% vol. concentration into the adhesive. The MENs were measured out and then dispersed into the hardener part of the epoxy. The hardener was then mixed into the base of the epoxy and the epoxy then used to depend on which test specimen was created. 


\section{D Materials}

The 3D graphene foam that was used for this thesis was purchased from Graphene Supermarket. The GrF was a 3D Multilayer Freestanding Graphene Foam. The 3D GrF was made through chemical vapor deposition (CVD) and is known as CVD Graphene Foam. Copper foam is used in a furnace where hydrogen and methane gasses were heated to $1000^{\circ} \mathrm{C}$ and decomposes to create graphene in a similar foam structure. To acquire the graphene foam, the copper foam was simply etched away. The graphene foam was selected to be used in combination with a simple marine epoxy. The graphene foam was simply placed into the adhesive using nonmagnetic tweezers in between the adherends.

\section{Microscale Double Cantilever Beam Specimens}

The microscale double cantilever beam $(\mu \mathrm{DCB})$ specimens were selected to be aluminum material. As discussed previously, each micro-DCB specimen are $27.5 \mathrm{~mm}$ long by $10 \mathrm{~mm}$ wide. In order to maintain optimal bond line consistency, the specimens were created using two plastic spacers and a release-ply material to create the pre-crack. Each plastic spacer has a thickness of $0.6 \mathrm{~mm}$ creating an overall ideal bond line of $1.2 \mathrm{~mm}$. The aluminum bar was cut into two pieces seen in Fig. 11, with a length of $50 \mathrm{~mm}$. The spacer was cut with an outside dimension of $40 \mathrm{~mm}$ by $50 \mathrm{~mm}$ with an inside cut-out of $30 \mathrm{~mm}$ by $30 \mathrm{~mm}$. To ensure proper surface preparation, the aluminum adherend was grit-blasted. The spacer is placed on top of the adherend, the adhesive being used was then placed within the spacer. The release-ply material then placed on top of the spacer so that the pre-crack of each specimen is approximately $12 \mathrm{~mm}$ long. The second spacer is then added on top and more adhesive added. Finally, the second adherend is placed on top. The whole specimen is then placed in a vacuum bag to minimize void content in the adhesive. 


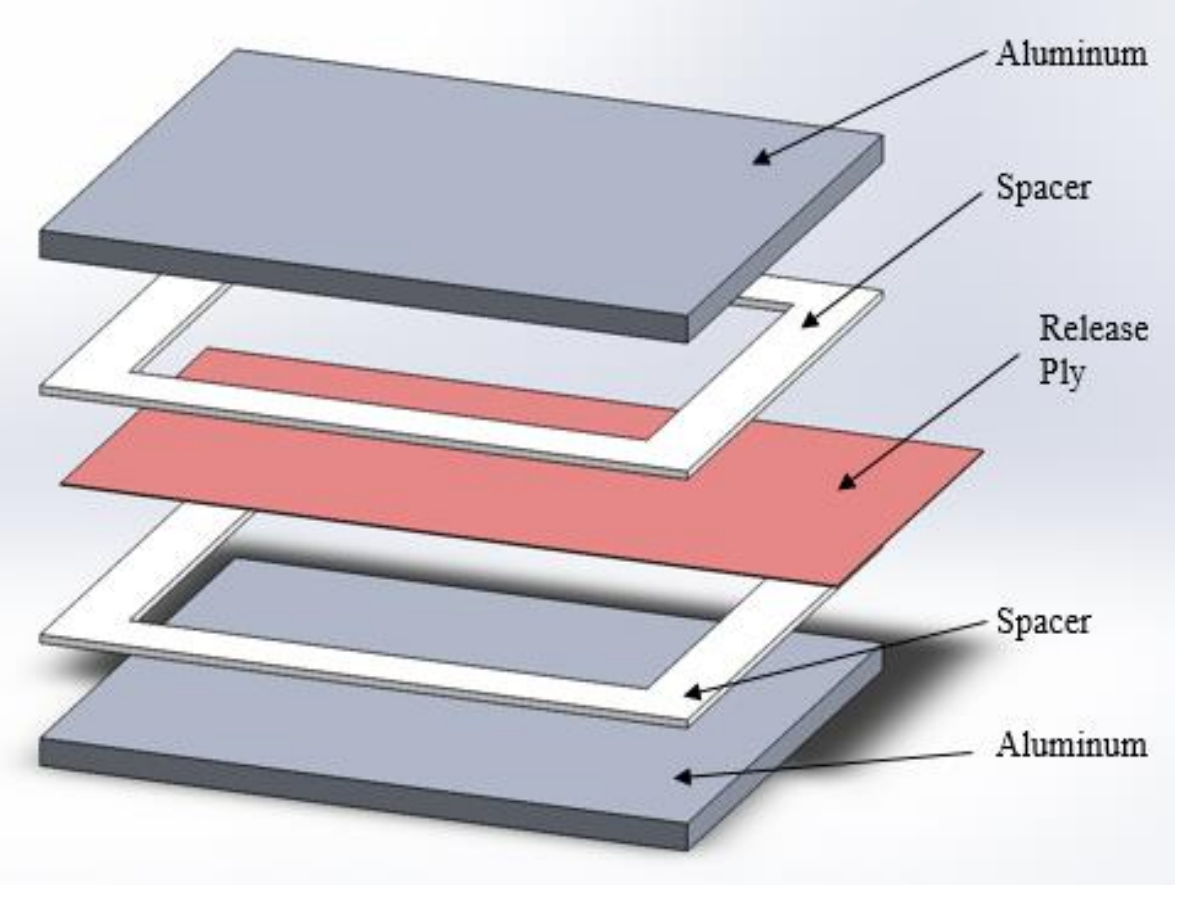

Figure 11. Micro-DCB exploded view

Once the specimen cure is completed, the actual micro-DCB specimens were cut using an abrasive waterjet to the size of $27.5 \mathrm{~mm}$ long by $10 \mathrm{~mm}$ wide. Fig. 12 shows the cutout dimension to be used in the waterjet cutting process. The cutout will allow for three samples to be cut in a single specimen. The cutout is designed so that the waterjet will cut within the open section without spacers. Effectively giving the cutout samples a purely adhesive bond line with the desired pre-crack length. 


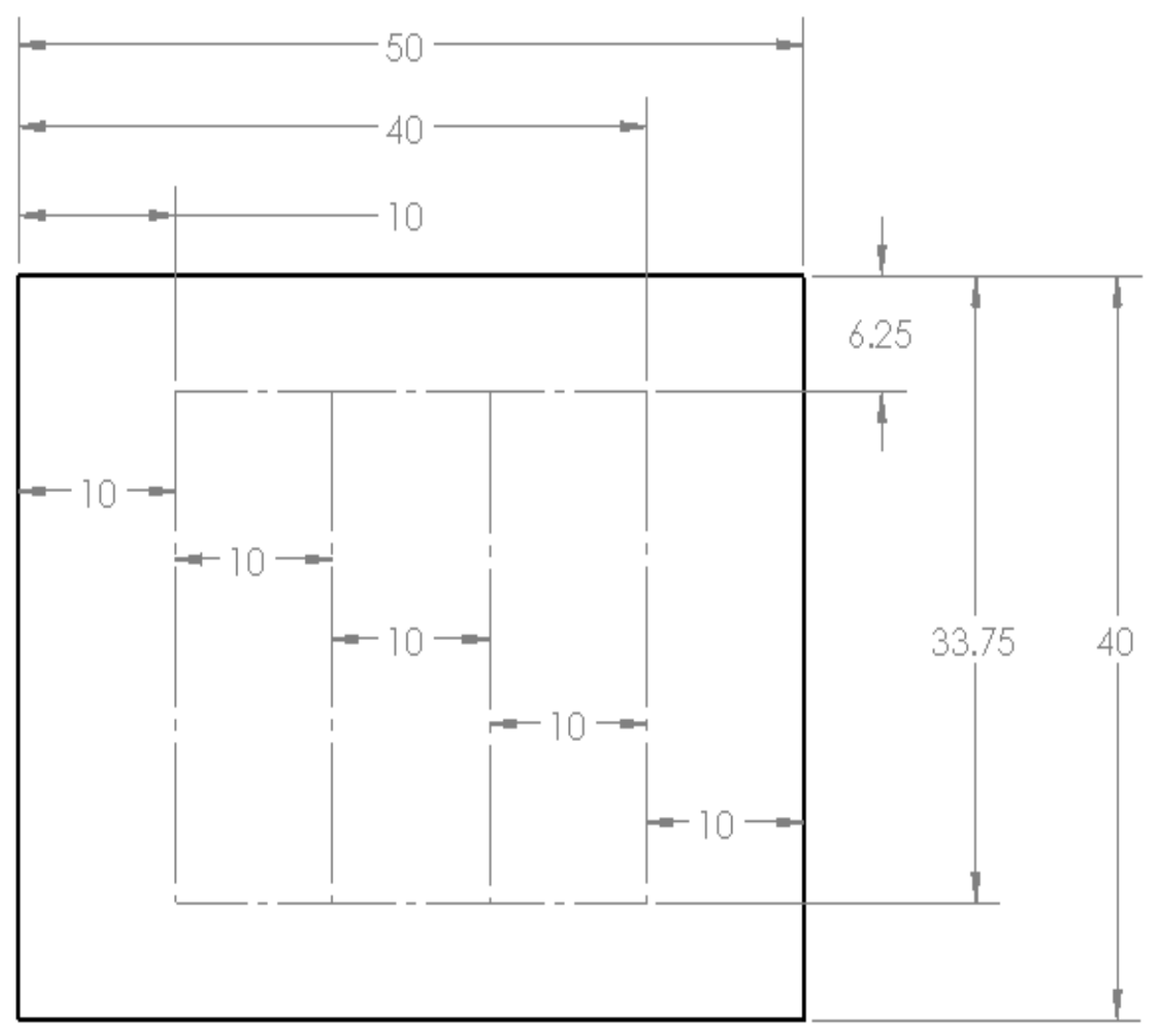

Figure 12. Micro-DCB cutout

\section{Microscale End Notch Flexure Specimens}

The microscale end notch flexure (ENF) specimens were created using unidirectional carbon fiber. The unidirectional carbon fiber panels were manufactured using Torray $\mathrm{T} 800 \mathrm{H}$ prepreg carbon fiber. The surface of the carbon fiber specimens was prepared using a polyester peel ply (Fibre Glast) during the curing of the panel. The first step in creating the micro-ENF specimens was to cut two panels $70 \mathrm{~mm}$ long by $60 \mathrm{~mm}$ wide. The direction of the carbon fiber was oriented to be perpendicular to the long side of the cut panels. Two spacers were prepared similar to the spacers used in the DCB specimens. The spacers were cut to have an outer dimension the same as the carbon fiber panel (70 $\mathrm{mm}$ long and $60 \mathrm{~mm}$ wide) and an inner dimension of $60 \mathrm{~mm}$ by $50 \mathrm{~mm}$. The 
panel is put together similar to the micro-DCB specimen, one carbon fiber adherend first, the spacer second, the release ply third, the second spacer fourth, and the second adherend last (Fig. 13). The adhesive will be added to the adherend after the first spacer and after the second spacer have been placed. The whole sample will be placed into a vacuum bag as well and cured for the required time depending on the adhesive.

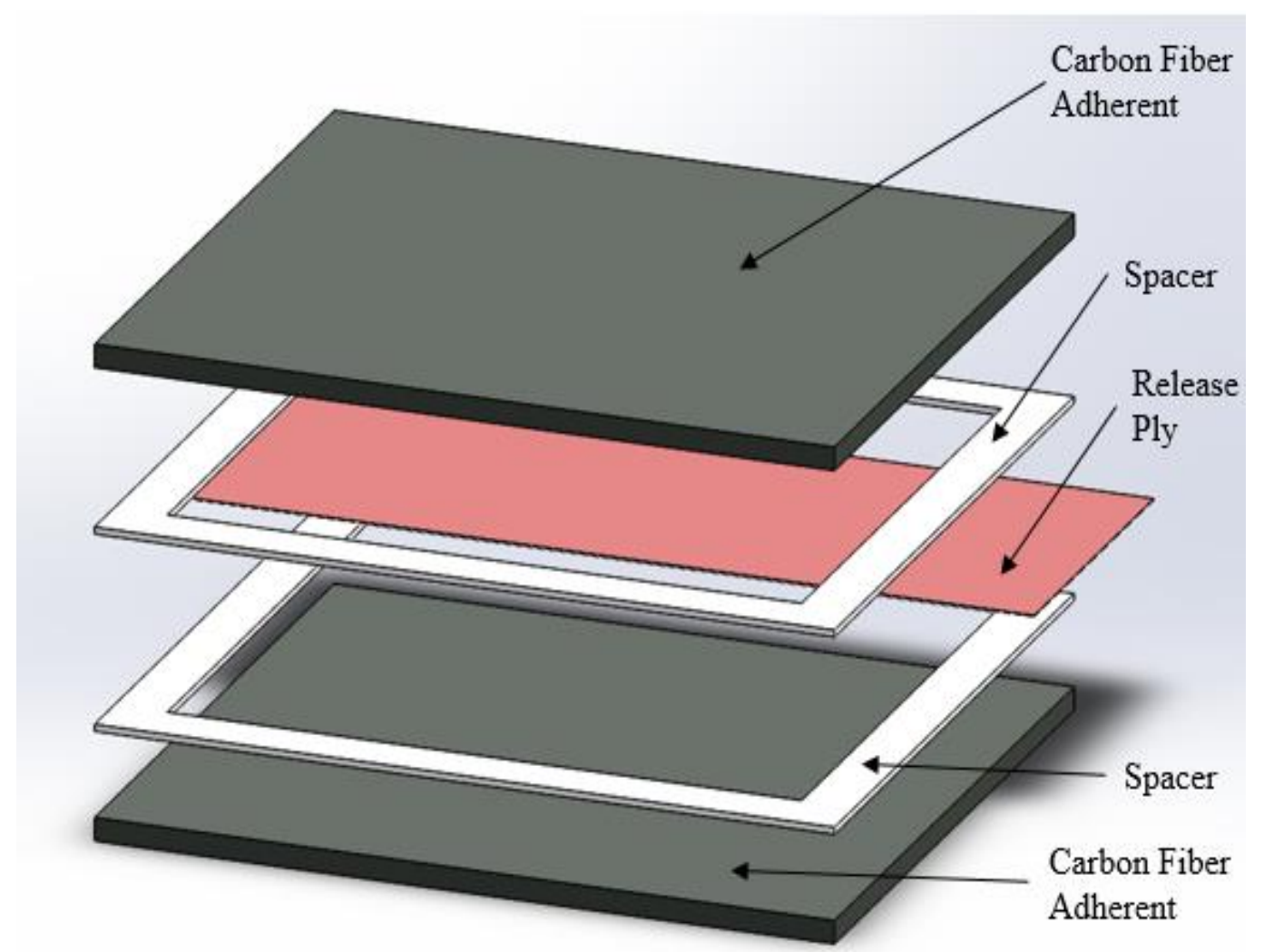

Figure 13. Micro-ENF exploded view

Once the curing is completed, the specimen will be cut using the abrasive waterjet cutter. The cutting will be done to cut samples as seen in Fig. 14. The specimen will be 40 $\mathrm{mm}$ long by $10 \mathrm{~mm}$ wide. Like the DCB cutouts, the cutout will allow for the waterjet to 
cut the individual micro-ENF specimen size from this larger specimen. The ENF will allow for five samples to be cut from this bonded panel.

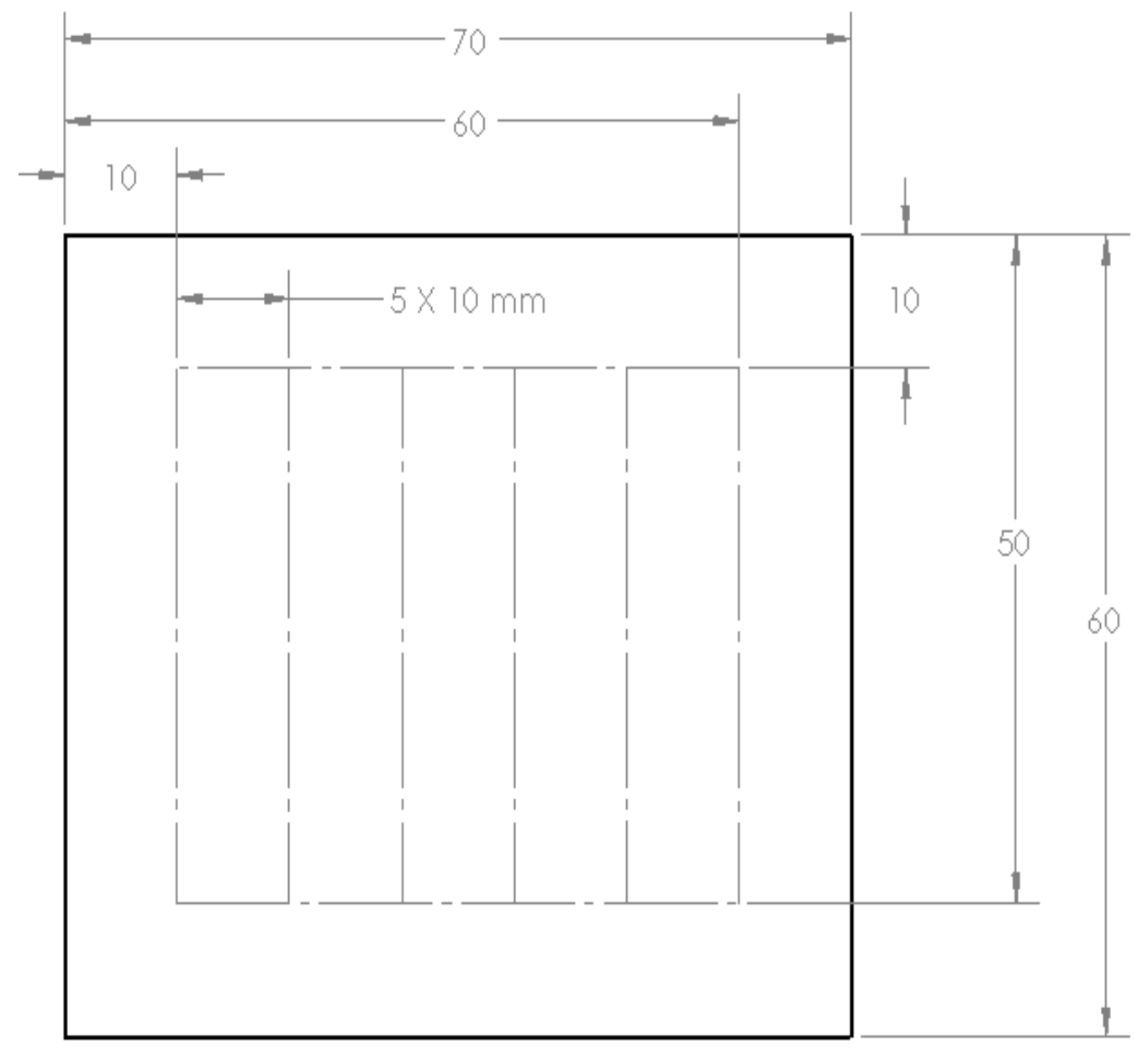

Figure 14. Micro-ENF cutout

\section{Test Development}

The overall goal of this research is to develop microscale fracture toughness tests for two different modes of failure; opening mode and sliding mode. The purpose of these tests is to be performed 4in situ, within the chambers of a SEM. Both tests will require a testing stage where the testing fixtures will be manufactured and used on. The stage that 
was used was the MTI Instruments SEM 1000 Tester (Fig. 15). This tester is a miniature tensile tester that is specifically designed to be used in microscopes. This tester can be used in a variety of different modes; tensile, compressive, fatigue, and bending. Either a $100 \mathrm{lb}$ $(\approx 440 \mathrm{~N})$ or a $1000 \mathrm{lb}(\approx 4440 \mathrm{~N})$ load cell can be used for the SEM Tester. The ENF and DCB fixtures were designed to fit within the stage. To accurately design the testing fixtures, the first step was to accurately design the stage tester. The entire stage tester was measured and modeled in SolidWorks. All tests were done using this stage tester within the Jeol 4500 FIB/SEM. Only the SEM portion of this machine was utilized, which has a magnification of up to $300,000 \mathrm{x}$ with a $5 \mathrm{~nm}$ resolution at a $30 \mathrm{kV}$ accelerating voltage.

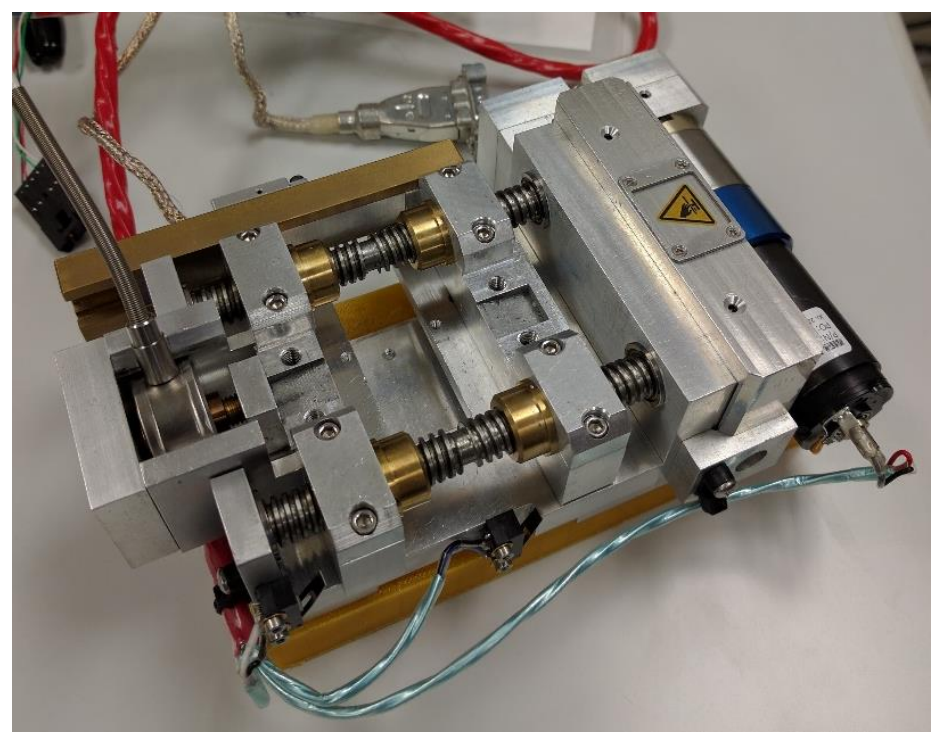

Figure 15. MTI Instruments SEM 1000 Tester

\section{Double Cantilever Beam}

The double cantilever beam test was the test method that was decided to be used for mode I of fracture. As discussed previously, the DCB test consists of two specimens bonded together having a pre-crack that is pulled in tension. Therefore, while designing the testing fixtures, a couple things had to be accounted for. The first thing is that the DCB 
specimens would need to be pulled at their ends in a tensile manner. This means that the fixtures would require a means to attach to a block or hinge that is attached to the specimen. For the macroscale DCB tests, simple door hinges are glued onto the ends of the specimen and then the other side of the hinges are placed in the mechanical (or pneumatic) grippers. Due to the orientation of the SEM Tester, this cannot be done for the micro DCB test because the direction of the crack growth must be perpendicular to the direction of the electron beam in the SEM. Multiple options were explored but the simplest mean of accomplishing this was to create a fixture that allowed for one side of a hinge to be attached through a small screw or bolt. Once the hinges were decided, the first iteration of the testing fixtures could be created. The first iteration of the fixtures had a flaw that the section attaching to the hinges was too large. This was preventing the stage from being able to pull the DCB specimen enough to propagate the crack. The solution to this was a redesign using smaller hinges and changing the fixtures. The hinges that would be used on the specimen are miniature surface-mount hinges that do not come with holes. The leaf height of these hinges is $5 \mathrm{~mm}$, the overall width is $14 \mathrm{~mm}$ and the leaf thickness is $1 \mathrm{~mm}$. These hinges can be purchased from McMaster-Carr. The testing fixture that needed to be created had two separate parts; end 1 and end 2 . End 1 is the fixture that attaches to the end of the stage that houses the load cell and end 2 is the other side. The fixtures can first be printed using a standard fused deposition modeling (FDM) 3D printer to verify the tolerances as well as showing the system set up (Fig. 16). Both fixtures can be easily designed using a computer aided design (CAD) program such as SolidWorks or AutoCAD by following the dimensions shown in Fig. 17 and Fig. 18. 


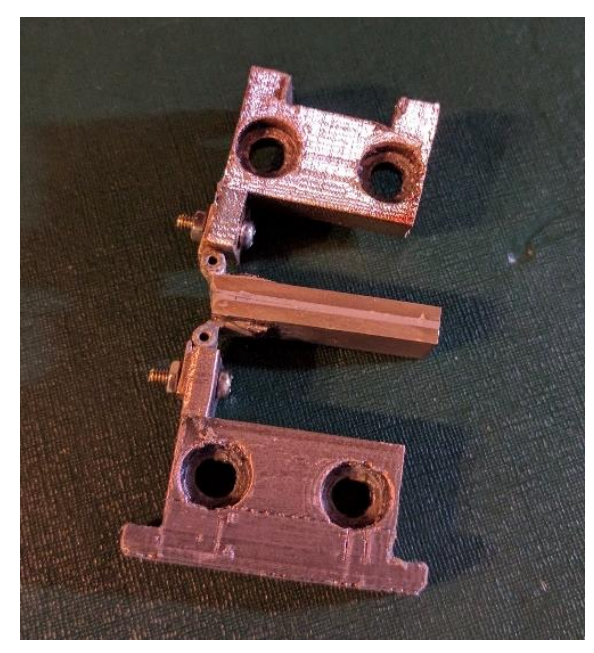

Figure 16. 3D printed fixtures attached to micro-DCB specimen.
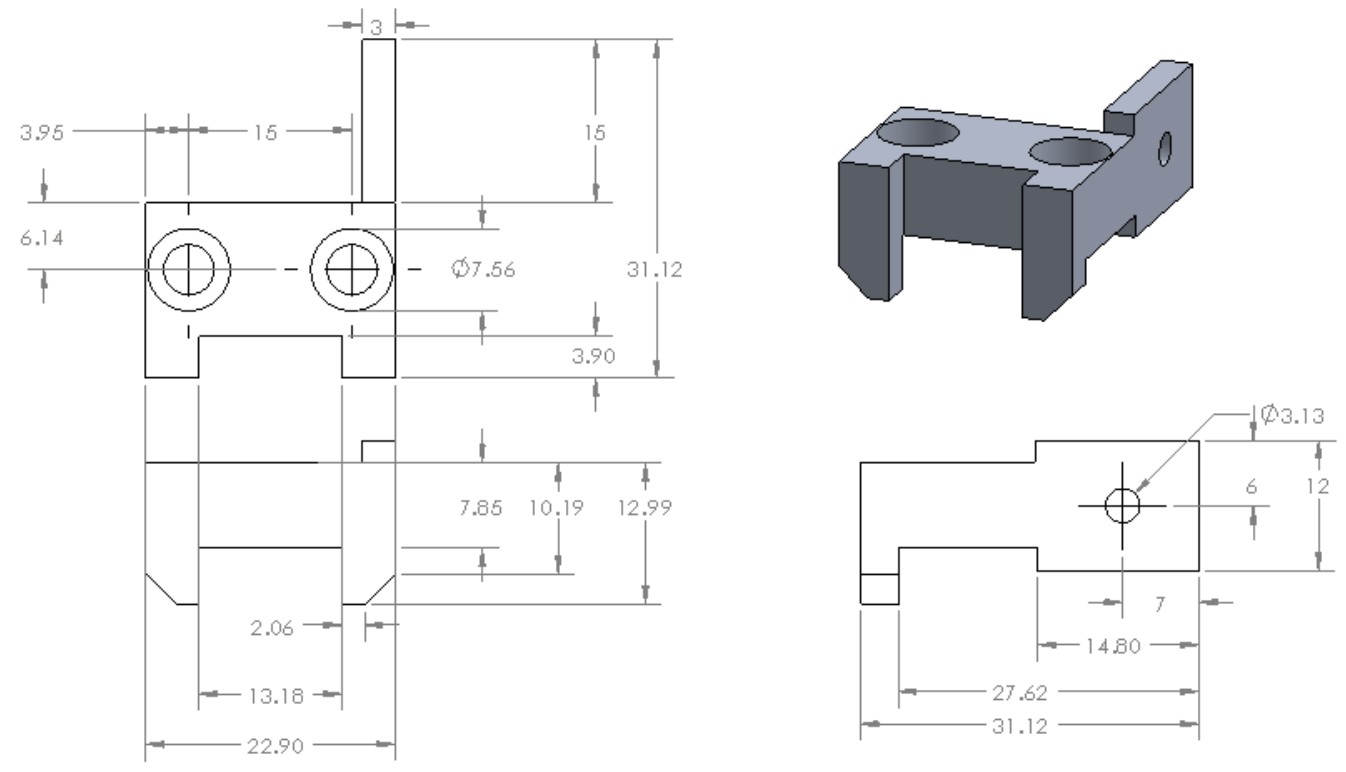

Figure 17. End 1 of micro-DCB testing fixture. 


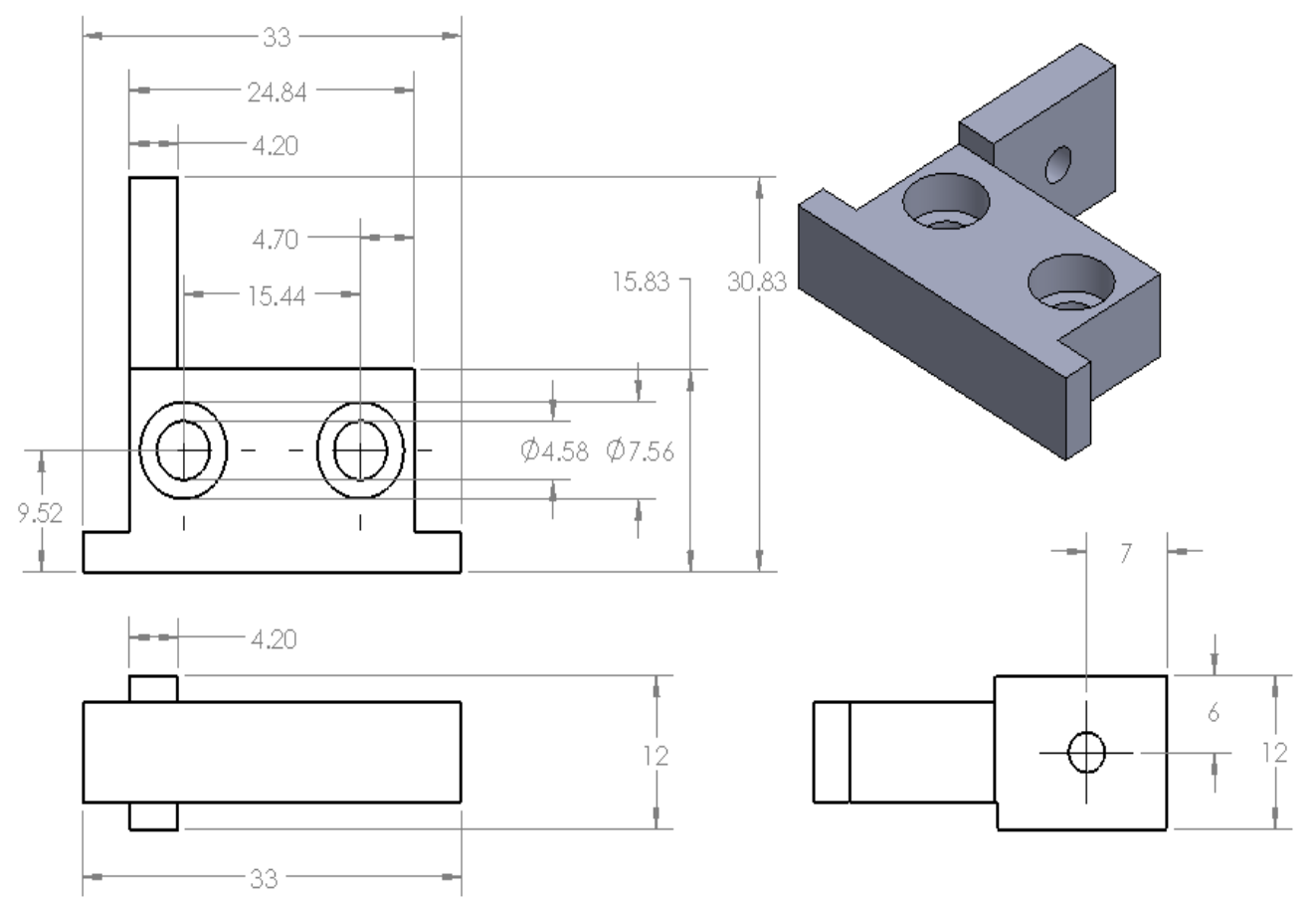

Figure 18. End 2 of micro-DCB testing fixture.

The next part of the test development process was to optimize the specimen size. Although, fracture toughness is typically considered a material property, geometry has been shown to influence the toughness values [71]. Therefore, scaling the DCB test down to a microscale will influence the fracture toughness values. One especially important value is the pre-crack length. This is vital because the pre-crack will have difficulty propagating if the pre-crack is too short. So, ideally, the pre-crack will want to be as short as possible while still being able to propagate. The adherend for the micro-DCB test will be made from an aluminum bar with a $2 \mathrm{~mm}$ thickness. The width of the specimen was initially based off the typically allowable z-height in the stage fixtures. The length was the maximum length allowable between the lead screws of the stage. The dimensions of the micro-DCB specimen can be seen in Fig. 19. The initial pre-crack length was originally designed to be 
$8 \mathrm{~mm}$ and increase by $2 \mathrm{~mm}$ until the crack was successfully able to propagate. This occurred at a $12 \mathrm{~mm}$ pre-crack length.
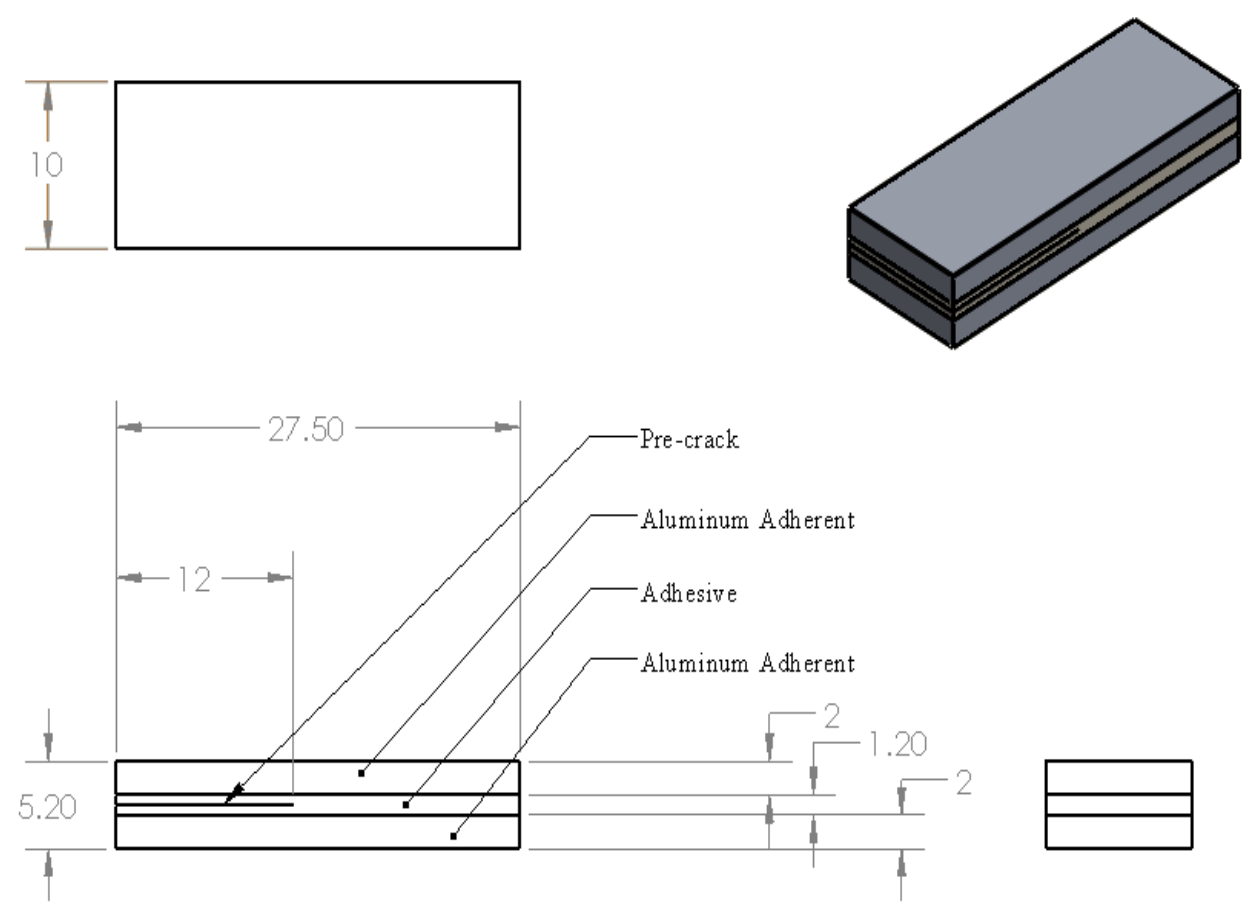

Figure 19. Micro-DCB specimen dimensions

\section{End Notch Flexure}

The end notch flexure (ENF) test was selected to be used for the fracture toughness test for mode II, sliding mode. The ENF test consists of two adherends bonded together using an adhesive with a pre-crack like the DCB specimen. The ENF test fixtures were designed so that either a three-point bend or a four-point bend. The fixtures configured in a three-point bend setup can be seen in Fig. 20. The fixtures have metal bars that are used to mount the micro-ENF specimen. The metal bars are floating bars, meaning they are not permanent fixtures. They are connected to the permanent fixture using small, rubber bands (dental bands) to supply enough tension to keep them in the correct location. 


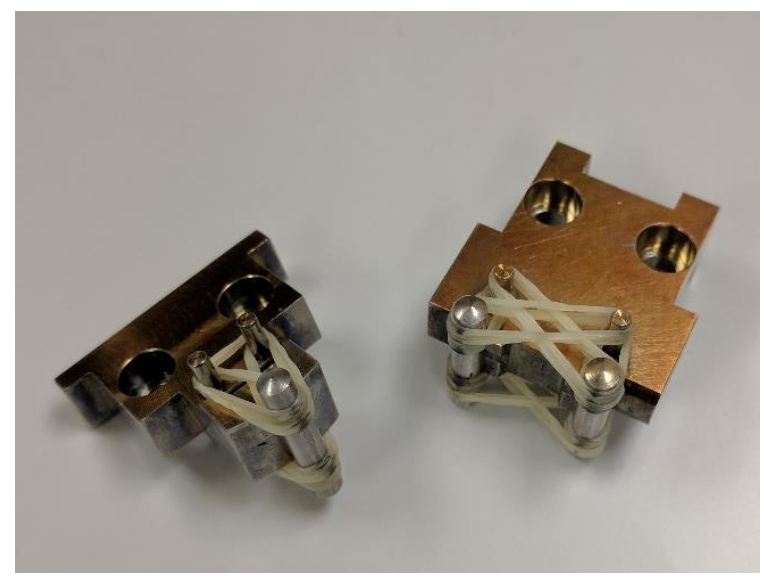

Figure 20. Micro-ENF fixtures configured in a three-point bend

Like the test in mode I, the mode II test will also be effected by the geometry of the specimen. The ENF specimen was made for the maximum size allowable in the stage tester. The adherend for all of the micro-ENF tests were made up of unidirectional carbon fiber laminates. The laminates are approximately $2 \mathrm{~mm}$ thick or 10 ply of the prepreg material. The ENF specimen consists of two carbon fiber adherends bonded with an adhesive. The adhesive will be approximately $1.2 \mathrm{~mm}$ thick created by the stacking of two $0.6 \mathrm{~mm}$ thick spacers. The pre-crack for the micro-ENF specimen is as important as it was in the microDCB specimen. The pre-crack was optimized to $12 \mathrm{~mm}$ in length similar to the micro-DCB specimen. Fig. 21 shows the micro-ENF specimen. 

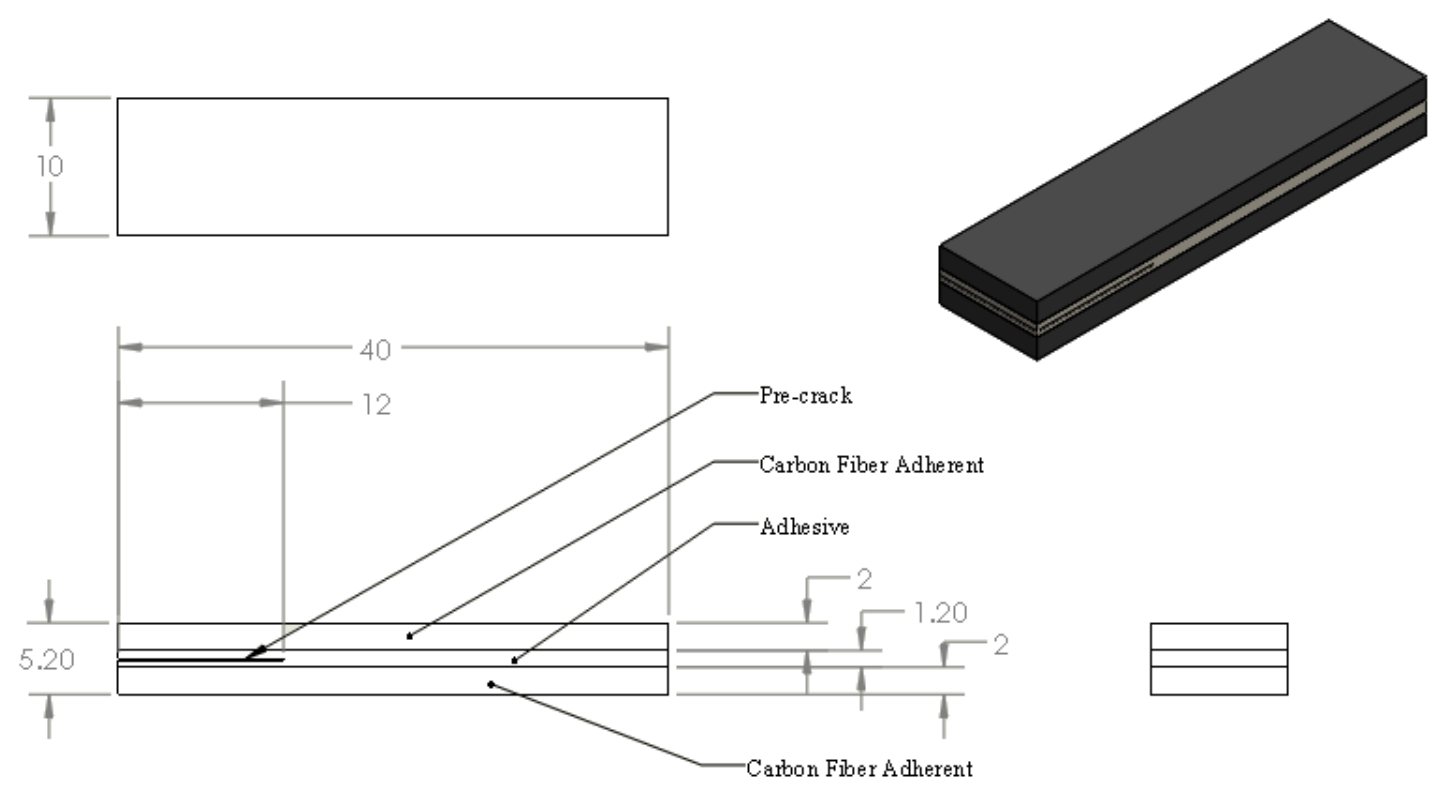

Figure 21. Micro-ENF specimen dimensions

\section{Adhesives and Adherends}

To ensure that the tests would work for a variety of different adhesives and adherends, three different adhesives were selected and tested for the two different tests selected. The adhesive would vary with the reinforcing agent being used. All the materials used in this research (including materials to create the composites, spacers, MENs, etc.) can be found in Table 3 .

Table 3. Materials

\begin{tabular}{|c|c|}
\hline $\begin{array}{c}\text { Prepreg Material for Carbon } \\
\text { Fiber Adherend }\end{array}$ & Toray T800H \\
\hline Peel Ply & Polyester Peel Ply (Fibre Glast) \\
\hline Breather Material & Polyethylene Breather and Bleeder \\
& (Fibre Glast) \\
\hline
\end{tabular}




\begin{tabular}{|c|c|}
\hline Release Ply & $\begin{array}{l}\text { Low Temperature Release Film } \\
\text { (Fibre Glast) }\end{array}$ \\
\hline Vacuum Bag & $\begin{array}{l}\text { Stretchlon } 200 \text { Bagging Film (Fibre } \\
\text { Glast) }\end{array}$ \\
\hline Vacuum Tape & Gray Sealant Tape (Fibre Glast) \\
\hline High Temperature Tape & Flash Tape (Fibre Glast) \\
\hline Spacer & Polycarbonate Sheet (0.6 mm thick) \\
\hline Adhesives & $\begin{array}{ll} & \text { Loctite Marine Two-Part Epoxy } \\
& \\
& \text { Applied Poleramic SC-15 Epoxy } \\
& \text { 3M Scotch-Weld EC-2615 B/A } \\
\text { Epoxy } & \end{array}$ \\
\hline $\begin{array}{l}\text { Magneto-electric } \\
\text { nanoparticles }\end{array}$ & $\begin{array}{l}\text { Deionized Water } \\
\text { Ethanol ( } 200 \text { proof) } \\
\text { Citric Acid } \\
\text { Titanium (IV) Isopropoxide } \\
\text { Barium Carbonate } \\
\text { Cobalt Ferrite } \\
\text { Cobalt (III) Nitrate Hexahydrate } \\
\text { Iron (III) Nitrate Nonahydrate } \\
\text { Polyvinylpyrrolidone } \\
\text { Sodium Borohydride }\end{array}$ \\
\hline GNP & XG Sciences xGNP-M-5 \\
\hline Graphene Foam & $\begin{array}{c}\text { Graphene Supermarket 3D } \\
\text { Multilayer Freestanding Graphene Foam }\end{array}$ \\
\hline
\end{tabular}




\section{CHAPTER IV - RESULTS AND ANALYSIS}

This chapter will report the experimental results of the micro-ENF and the microDCB testing for each one of the nanomaterial type of reinforcing agents. The testing of the magnetoelectric nanoparticle reinforced adhesive will be first, analyzing both the microENF tests as well as micro-DCB tests. The two-dimensional particle reinforcing agent, the GNP, will then be discussed. Both micro-ENF and micro-DCB tests were performed for the GNP doped adhesives. Finally, both micro-ENF and micro-DCB test results will be discussed for the graphene foam doped adhesives.

\section{Magnetoelectric Nanoparticles}

The first nanomaterial reinforcing agent that was investigated was the magnetoelectric nanoparticles (MENs). The MENs were successfully created using the method previously described to a $30 \mathrm{~nm}$ diameter, this was previously verified using TEM imaging (Fig. 6). The MENs were doped into the adhesive using a hand mixing technique, where the nanoparticles were mixed into the less viscous hardener. The MENs doped adhesives were the most extensively tested of all the reinforcing agents. This was done to ensure consistency of the test data as this was the first testing performed. Three of the undoped adhesive specimens and three of the doped adhesive specimens were tested for the micro-ENF. One undoped and one doped adhesive specimen was tested for the microDCB.

\section{End Notch Flexure}

The end notch flexure (ENF) specimens were manufactured through a modification of the standard macroscale geometry and were tested using the testing parameters found in ASTM D7905. The undoped adhesive was first tested using the micro-ENF setup. Fig. 22 
shows the load displacement curve for the three samples $(A, B, \& C)$ of the undoped adhesive ENF specimens. This curve showed a couple of important things. The first was the initial nonlinearity which is caused by the compliance of the fixtures themselves. This will be present in each of the micro-ENF tests and consistent with the macroscale tests. The second important thing the consistency. Although the curves seem to have a much different displacement at the same loads, this was attributed to the compliance of the fixtures for each of the individual tests. The initial nonlinear portion for Sample A was higher than in Sample C, and Sample B had the largest nonlinear portion. However, the samples reached a consistent maximum load. The third important thing that was noticed was the amount of displacement. In the undoped micro-ENF tests, a phenomenon was observed that was different from all the other tests. The samples failed (thus ending the test) before the limit of the testing procedures ( $2 \mathrm{~mm}$ displacement). This was attributed to the quality of manufacturing of the carbon fiber panels that were used as an adherend. SEM imagery showed clear interlaminar failure occurring in the adherend, which would lead to the test failing before the limit was reached (shown in Fig. 23). 


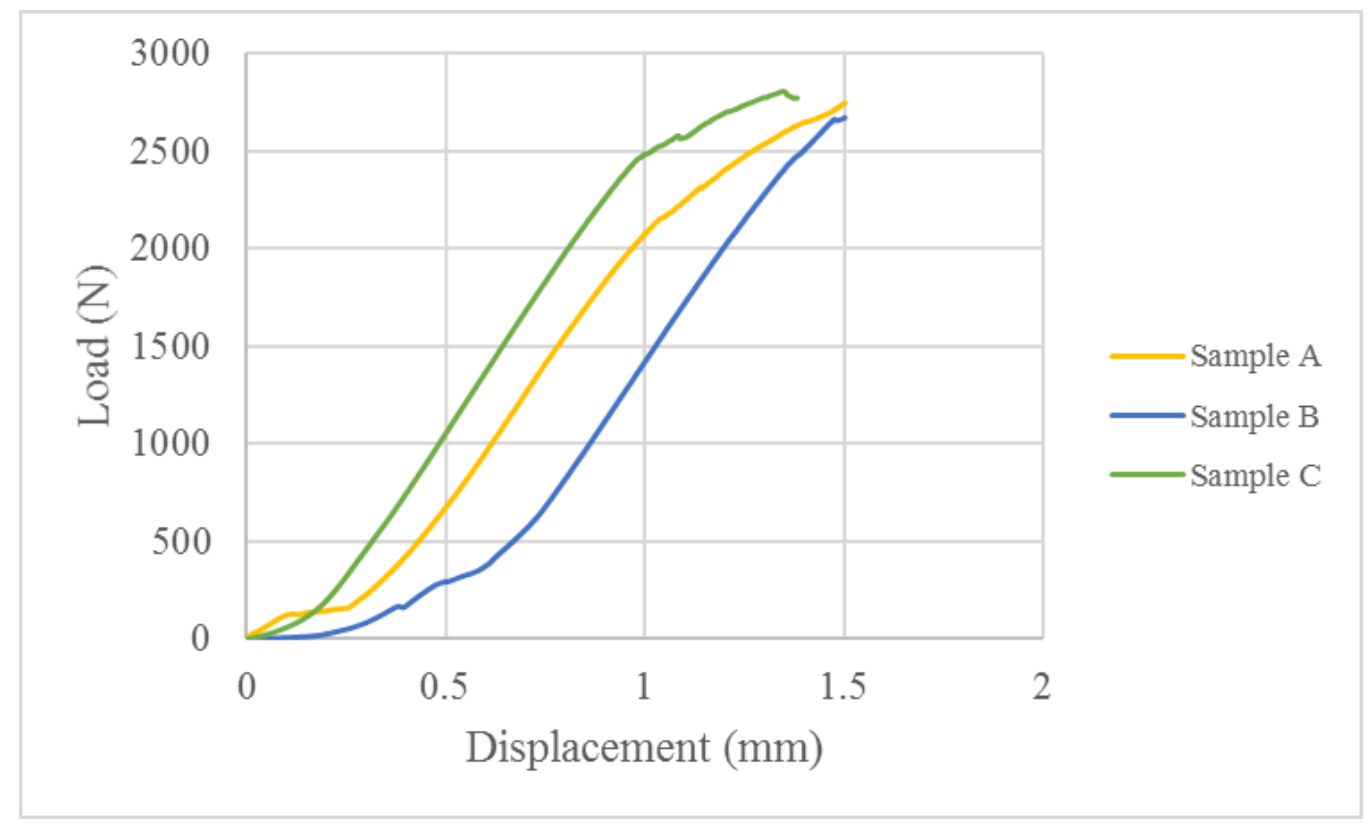

Figure 22. Load displacement curves for micro-ENF, undoped adhesive specimens.

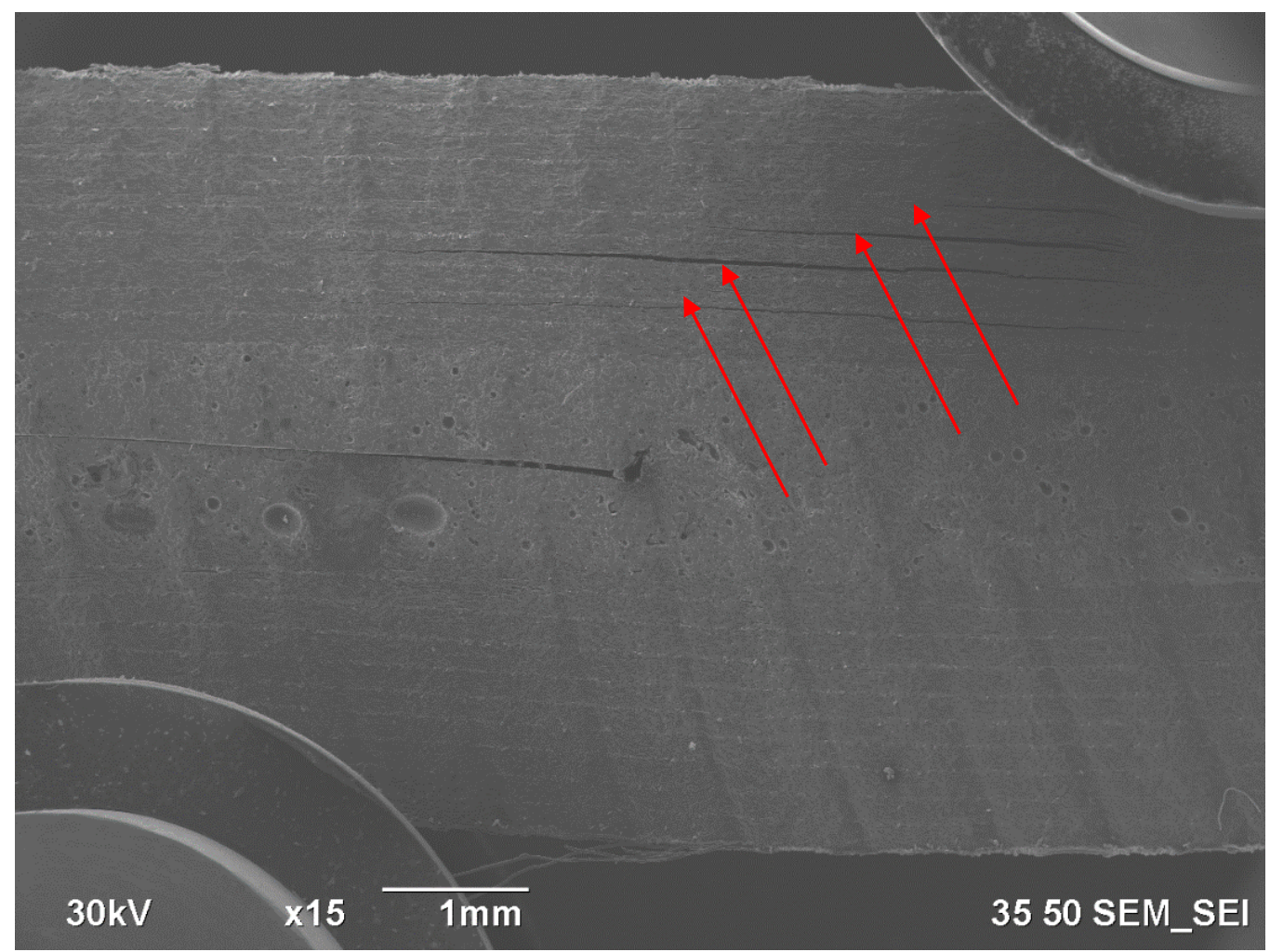

Figure 23. SEM images of interlaminar failure within the adherend

Three micro-ENF specimens with the MENs doped adhesives were tested as well. The load displacement curves for the doped specimens showed a much more 
consistent initial nonlinear portion compared to the undoped specimens (Fig. 24). The overall load displacement curves also show a more consistent behavior with close maximum loads. The displacement was also the full $2 \mathrm{~mm}$ of the stage tester for all three tests. SEM imagery of the crack tip region shows an initial state of the crack tip region (Fig. 25a). After testing, the crack tip region showed local shear loading as well as crack propagation. Additional to the crack propagation, localized damage was observed outside the plastic zone of the crack tip region (Fig. 25b and 25c).

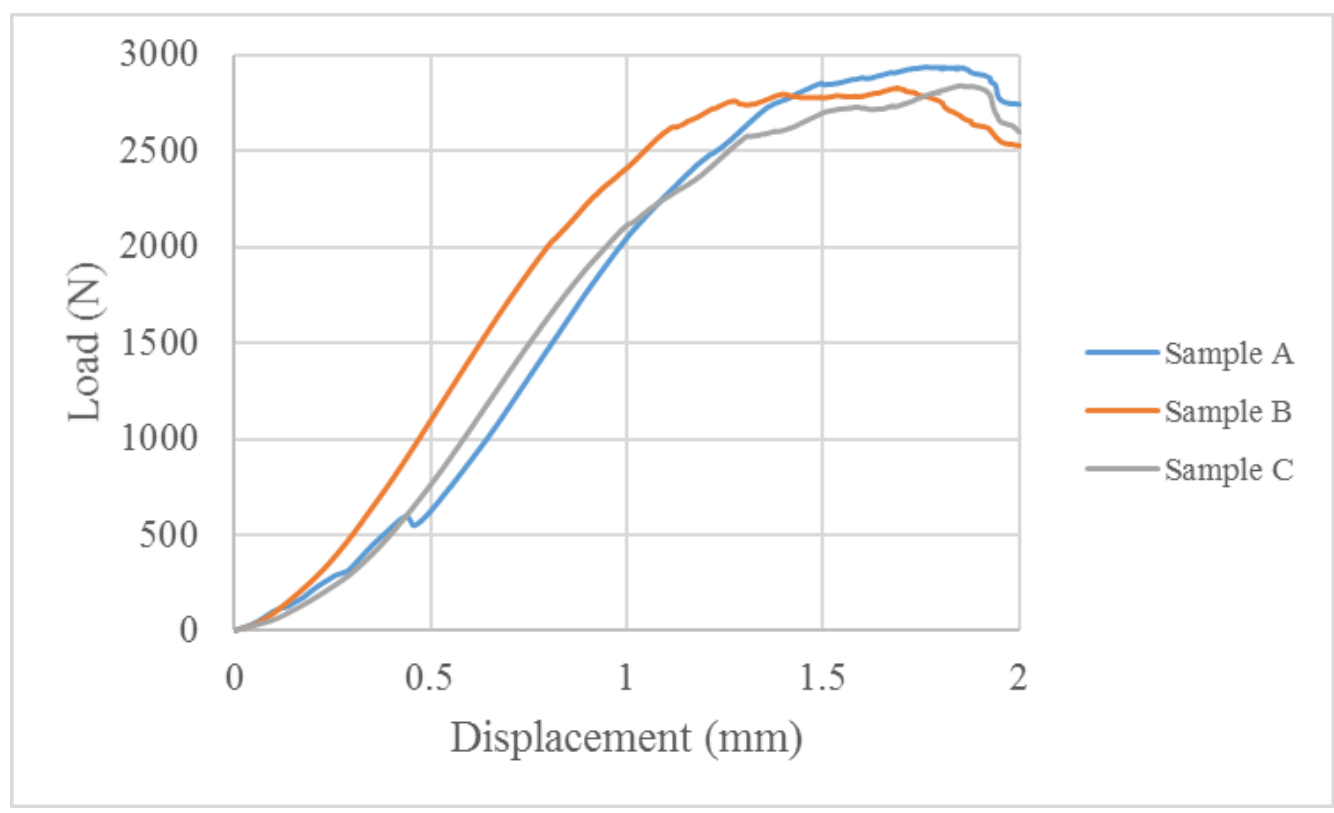

Figure 24. Load displacement curves for micro-ENF, undoped adhesive specimens.

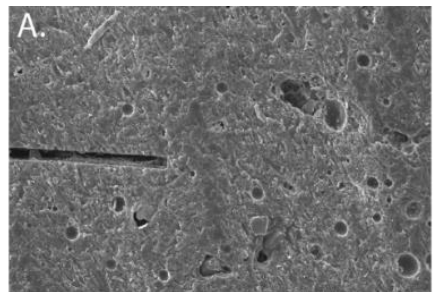

Initial State

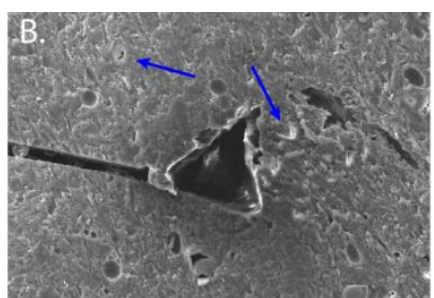

Deformed State $\quad-100 \mu \mathrm{m}$

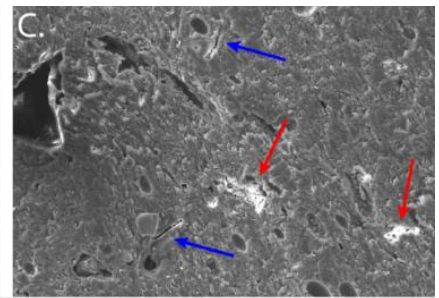

$200 \mu \mathrm{m}$

Figure 25. Still images of the in situ loaded ENF specimen. A) Pre-loading crack tip region. B) and C) Crack tip region after loading occurs showing areas of damage that initiated outside of the plastic zone region (blue arrows) and initial microvoid coalescence in high shear areas (red arrows). 
Table 4. Fracture toughness of undoped versus MENs doped adhesives.

\begin{tabular}{|l|l|l|l|l|l|l|}
\hline \multirow{2}{*}{ Sample } & \multicolumn{2}{|l|}{ Undoped } & \multicolumn{2}{l|}{ Doped } \\
\cline { 2 - 7 } & Load (N) & $\begin{array}{l}\text { Displacement } \\
(\mathbf{m m})\end{array}$ & $\begin{array}{l}\text { GIIC } \\
(\mathbf{k J / m} / \mathbf{m})\end{array}$ & Load (N) & $\begin{array}{l}\text { Displacement } \\
(\mathbf{m m})\end{array}$ & $\begin{array}{l}\text { GIIC } \\
\left(\mathbf{k J} / \mathbf{m}^{\wedge} \mathbf{2}\right)\end{array}$ \\
\hline 1 & 749.46 & 1.50 & 0.51 & 2934.87 & 1.76 & 0.58 \\
\hline 2 & 2674.01 & 1.50 & 0.47 & 2828.76 & 1.69 & 0.54 \\
\hline 3 & 2808.04 & 1.38 & 0.53 & 2839.12 & 1.85 & 0.58 \\
\hline Average & & & $\mathbf{0 . 5 0}$ & & & $\mathbf{0 . 5 6}$ \\
\hline
\end{tabular}

Table 4 shows the calculated fracture toughness values calculated by Eq. 18 , where $m$ is the slope of the linear region of the load displacement curves, $P_{\max }$ is the maximum load, $a_{0}$ is the precrack length, and $B$ is the specimen width. The fracture toughness values for the undoped specimen showed a typical fracture toughness value for epoxy adhesives around $0.50 \mathrm{~kJ} / \mathrm{m}^{2}$. The doped adhesive samples showed an average of $0.56 \mathrm{~kJ} / \mathrm{m}^{2}$ which was an increase of $12 \%$ in the fracture toughness values. Additionally, when the GIIC values are plotted against their respective displacements (Fig. 26), the MENs doped adhesive samples showed an increase in rigidity. For micro-ENF testing, the MENs doped adhesive showed an overall improvement compared to the undoped adhesive.

$$
G_{I I C}=\frac{3 m P_{\max }{ }^{2} a_{0}{ }^{2}}{2 B}
$$




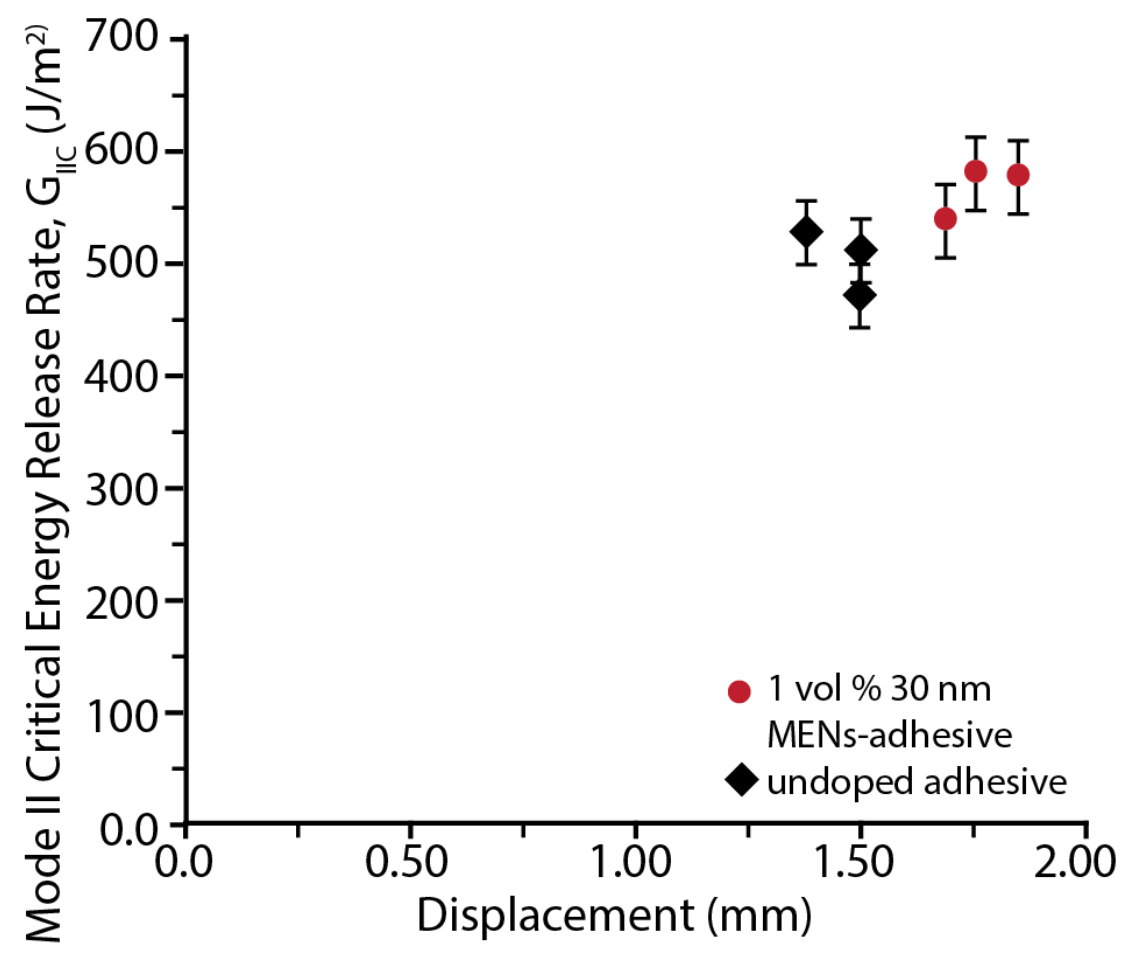

Figure 26. GIIC values of undoped and MENs doped adhesives.

\section{Double Cantilever Beam}

The double cantilever beam (DCB) specimens were tested from modifying the parameters found in ASTM D5528. The undoped adhesive was first tested using the microDCB setup. Fig. 27 shows the load displacement curve for both the undoped and doped adhesive samples. The plot showed the initial nonlinearity which is caused by the compliance of the fixtures themselves. This initial portion showed a large displacement for the doped sample and a much smaller amount of compliance for the undoped sample. Both the doped and the undoped sample showed similar load displacement curves. The pure adhesive specimen failed at approximately $58 \mathrm{~N}$ and displayed typical "adhesive" fracture where the failure occurred at the interface between the adhesive and the adherend (Fig. 28). The MENs doped adhesive failed at approximately $64 \mathrm{~N}$, which is an approximate $10 \%$ 
increase in the maximum load. The MENs doped adhesive exhibited slightly different fracture behavior, which exhibited a mixture of both "cohesive" and "adhesive" fracture (Fig. 29). The crack tip started to propagate through the adhesive, which is "cohesive" fracture, then propagated to the adherend and continued to fail between the adhesive and the adherend. The total fracture energy during these tests, approximated by the area under the load displacement curve, was approximately $33 \%$ higher in the MENs doped sample.

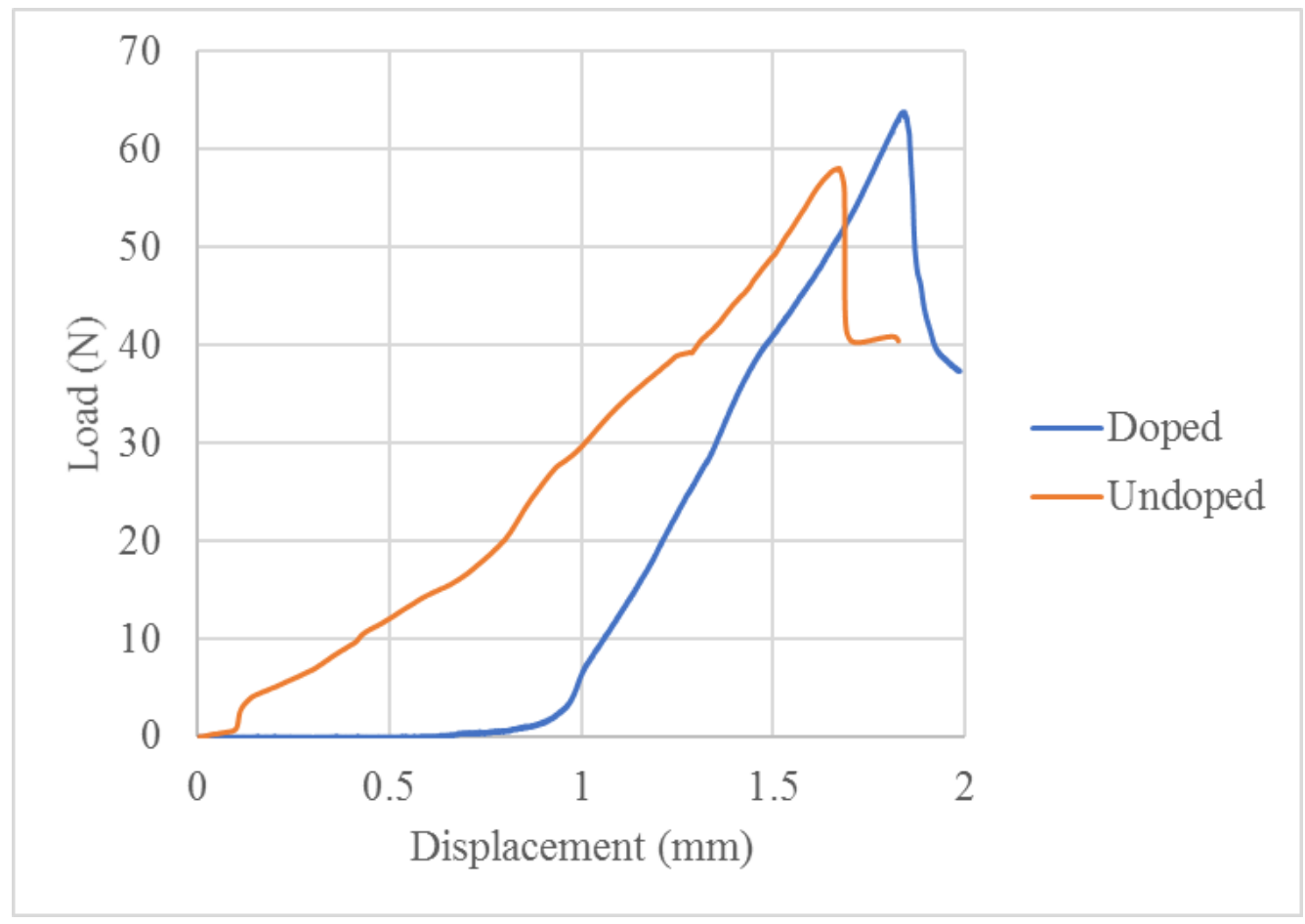

Figure 27. Load displacement curves for micro-DCB, undoped and MENs doped adhesive specimens. 

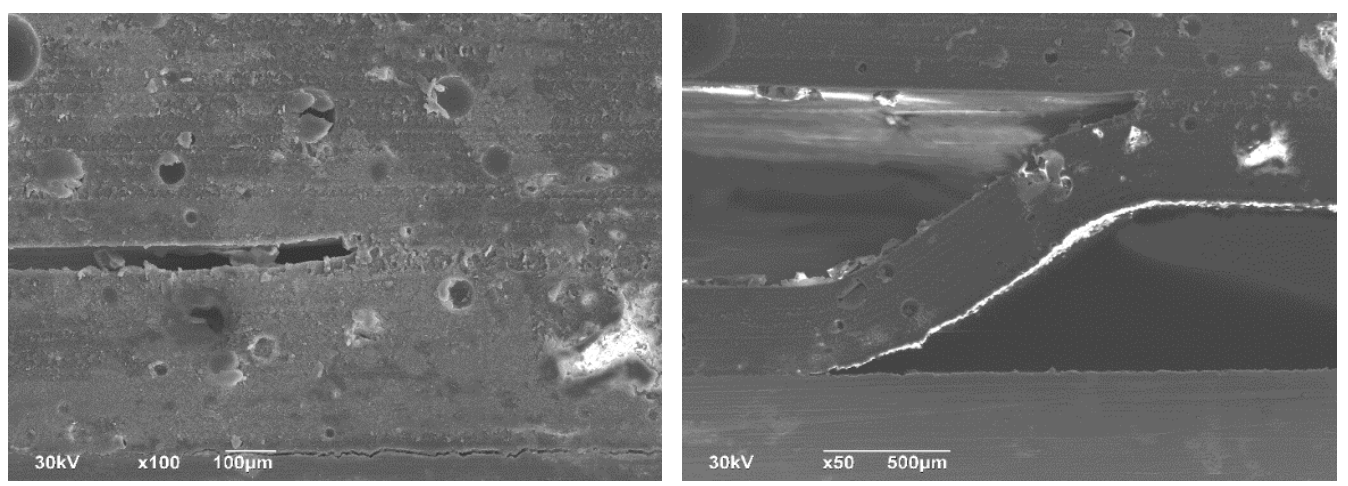

Figure 28. SEM still images of undoped micro-DCB sample. A) Prior to loading. B) Post loading.
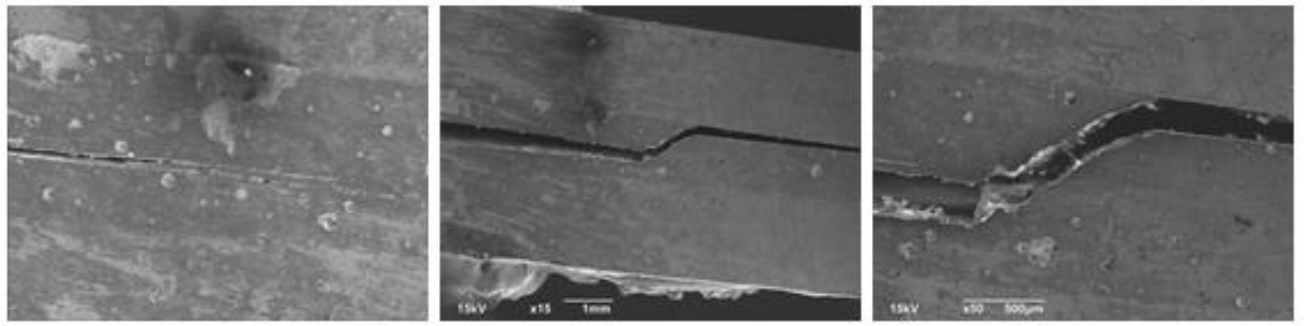

Figure 29. SEM images of MENs doped micro-DCB specimens. A) Prior to loading, B) and C) Post loading.

\section{D Materials - GNP}

The second nanomaterial reinforcing agent that was investigated was for the twodimensional material, graphene nanoplatelets (GNP). The adhesive was doped using tipsonicated GNP. The GNP doped adhesive was tested and compared to the undoped adhesive for the micro-ENF test. The GNP doped adhesive was solely tested for the microENF test and not compared to the undoped case.

\section{End Notch Flexure}

The micro-ENF test for the GNP doped adhesive showed similar to trends to the previous micro-ENF testing. The initial portion of the load displacement curve showed an initial nonlinear portion that can be attributed to the testing fixtures. The maximum load for the GNP doped adhesive showed a much lower maximum load $(\sim 1800$ N), which could be due to the adhesive used with the GNP. SEM images (Fig. 30) showed 
the crack tip region prior to and post loading, where a much smaller crack propagation was observed. The crack tip area also seemed to have a crack under the observable surface that can barely be seen in the still images.
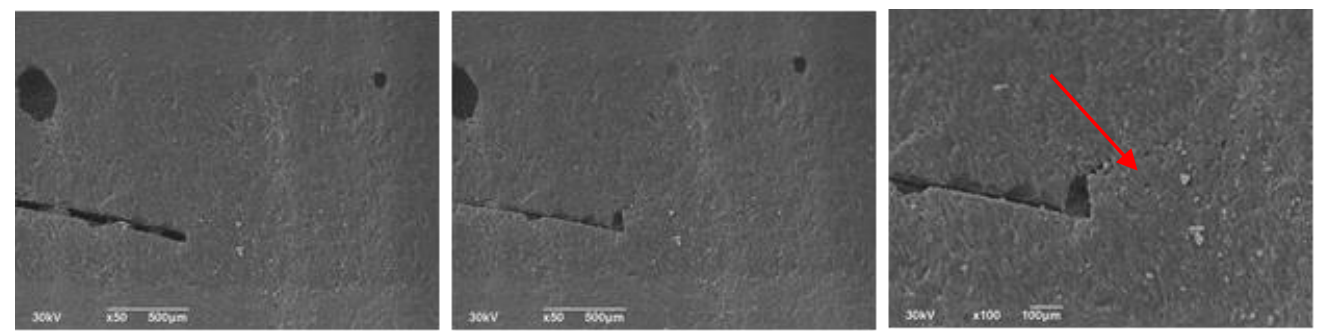

Figure 30. SEM still images of GNP doped adhesive micro-ENF test. A) Prior to loading. B) and C) Post loading.

\section{D Materials - Graphene Foam}

The last nanomaterial reinforcing agent that was investigated was the threedimensional material, graphene foam $(\mathrm{GrF})$. The adhesive was doped using multilayer freestanding graphene foam. The GrF doped adhesive was tested and compared to the undoped adhesive for both the micro-ENF test and the micro-DCB test. One of each specimen (the doped and undoped) was used for each test to assess the effects of the threedimensional graphene foam.

\section{End Notch Flexure}

Like previous tests, the GrF tests exhibited large initial nonlinear portions due to the compliance of the fixtures (Fig. 31). The undoped adhesive sample showed a maximum load of $3333.27 \mathrm{~N}$ at a displacement of $1.75 \mathrm{~mm}$ and the doped adhesive sample showed a maximum load of $3853.87 \mathrm{~N}$ at $1.96 \mathrm{~mm}$. The doped $\mathrm{GrF}$ adhesive sample showed a $15.62 \%$ increase in the maximum load. The mode II fracture toughness values were calculated for both the undoped and doped samples (Table 5). The GiIc value for the 
undoped adhesive sample was found to be $0.7093 \mathrm{~kJ} / \mathrm{m}^{2}$ and for the doped sample was found to be $0.9482 \mathrm{~kJ} / \mathrm{m}^{2}$, which is about a $33.68 \%$ improvement.

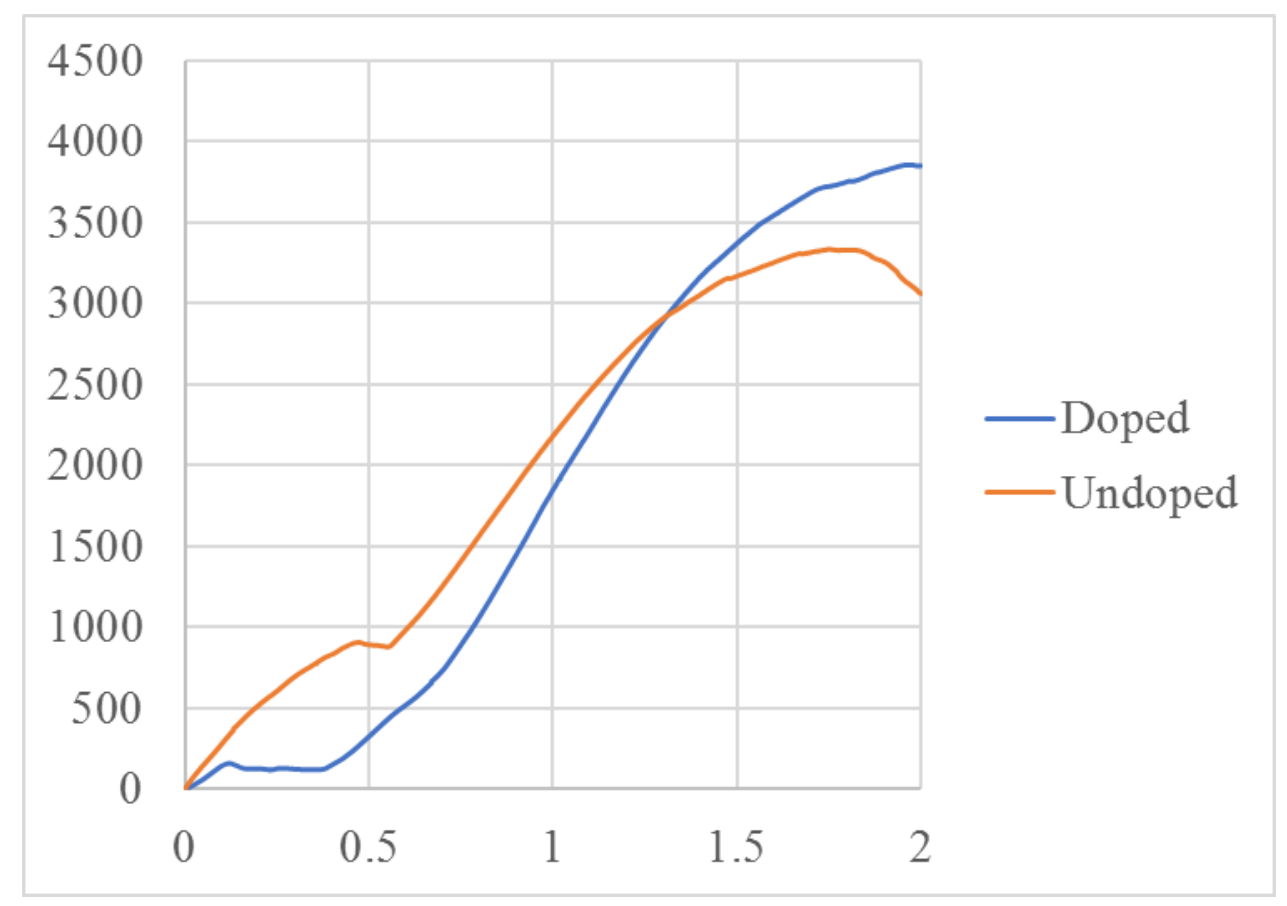

Figure 31. Load displacement curves for micro-ENF undoped specimens versus GrF doped specimens.

. Load displacement curves for micro-ENF

Table 5. Fracture toughness of undoped versus GrF doped adhesives.

\begin{tabular}{|l|r|r|r|}
\hline Sample & Load (N) & Displacement $(\mathbf{m m})$ & \multicolumn{2}{|l|}{ GIIC (kJ/m^2) } \\
\hline Undoped & 3333.27 & 1.75 & 0.7093 \\
\hline Doped & 3853.87 & 1.96 & 0.9482 \\
\hline
\end{tabular}

The undoped adhesive samples showed the precrack propagate towards the adherend after loading occurred. Fig. 32a showed the crack tip region prior to any loading where voids can be seen. These voids are due to the manufacturing processes during the adhesive curing. Fig. 32b and Fig. 32c showed the crack propagate towards the adherend 
during the shearing of the specimen. Like the other micro-ENF tests, localized damage was seen throughout the adhesive in front of the plastic zone near the crack tip region.
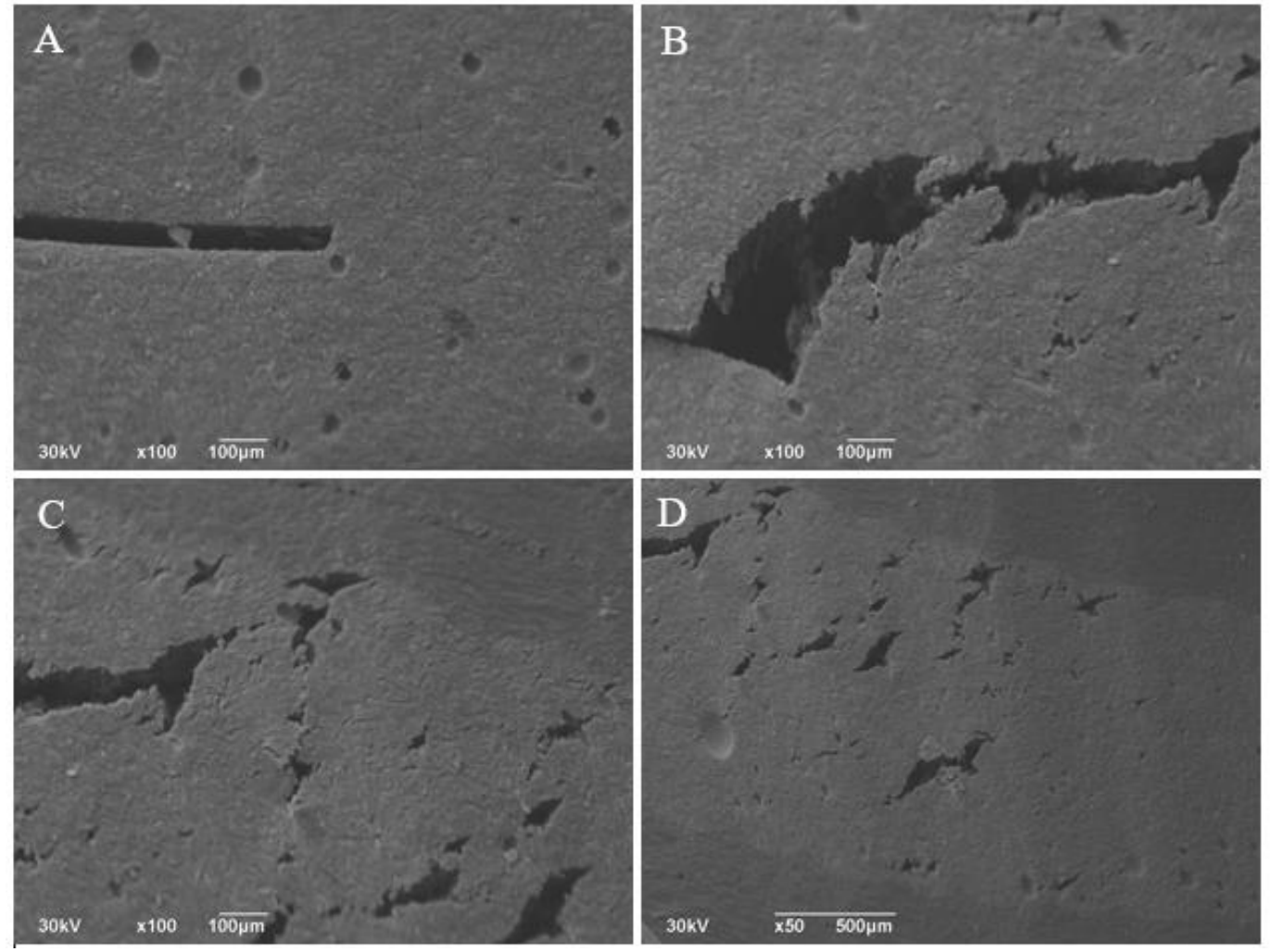

Figure 32. SEM images of adhesive sample a) prior to loading, b) and c) after loading. d) Lower magnification image of adhesive zone in front of crack tip region.

The graphene foam doped adhesive showed much less damage near the crack region. The sample showed crack propagation from the initial precrack (Fig. 33b and c) but then the crack steps out following the branches of the graphene foam, essentially allowing for the dissipation of energy. The crack continued propagating through the GrF 
reinforced adhesive (Fig. 33d). Unlike the undoped adhesive, the GrF reinforced adhesive shows minimal damage outside of the plastic zone area of the crack tip.
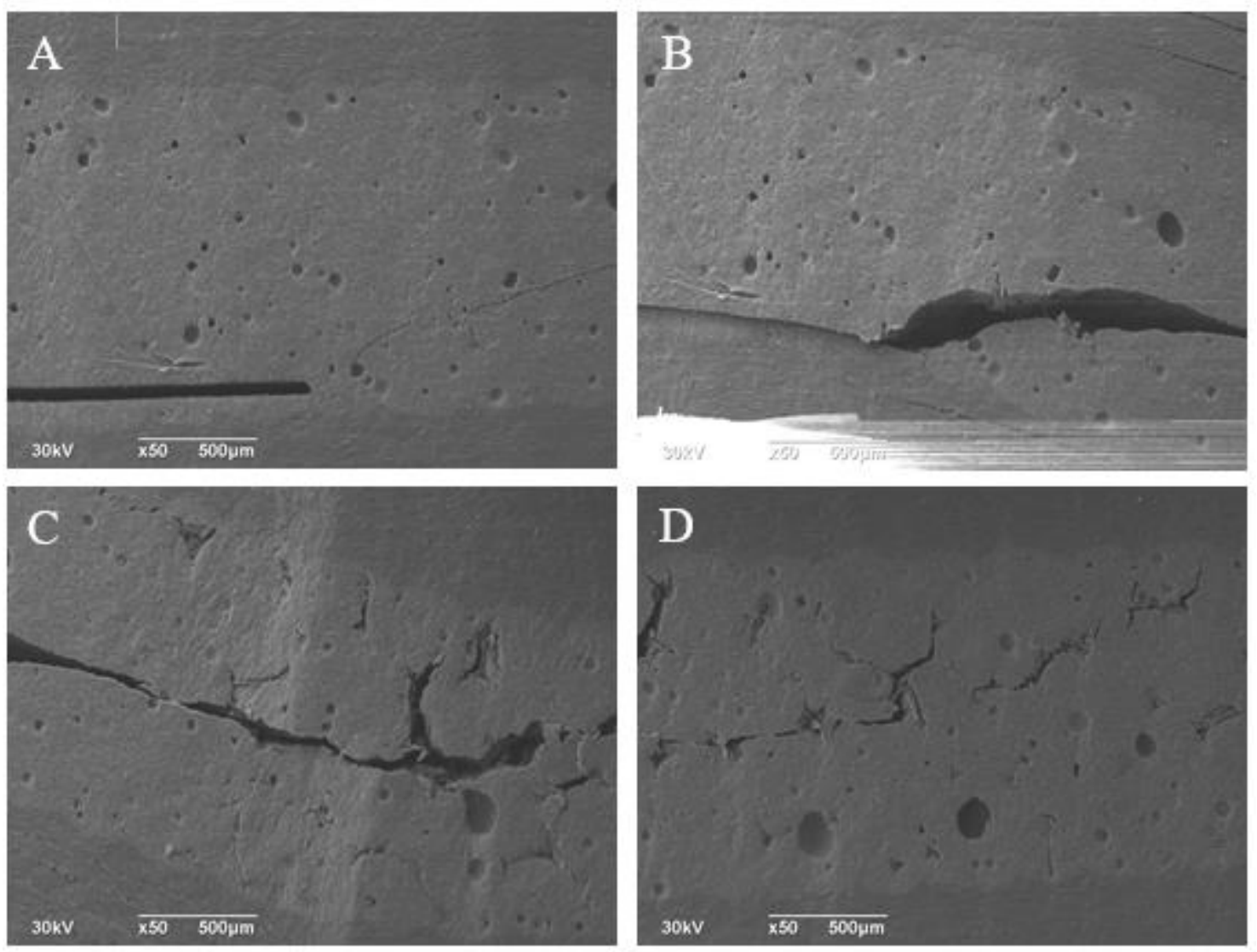

Figure 33. SEM images of GrF doped adhesive sample a) at the crack tip prior to loading, $b$ ) at the crack tip post loading, $c$ ) near the crack tip post loading, and d) end of propagated crack.

\section{Double Cantilever Beam}

The micro-DCB plot for the GrF doped adhesive and the undoped adhesive showed an initial nonlinear portion as in every previous test (Fig. 34). The GrF doped adhesive showed an approximate $40 \%$ increase in maximum load compared to the undoped adhesive; $51.2 \mathrm{~N}$ and $36.56 \mathrm{~N}$ respectively. The undoped adhesive samples failed in a typical "adhesive" fracture mode, where the precrack fails directly to the interface between the adhesive and the adherend (Fig. 35). The GrF doped adhesive had a "cohesive" fracture 
mode through the center of the adhesive. Additionally, the crack propagated in unique patterns frequently rising and falling vertically as much as $500 \mu \mathrm{m}$ as well as even propagating in the reverse direction (Fig. 36). The total fracture energy for the GrF doped adhesive sample was approximately $71 \%$ higher than the undoped sample. Another significant finding was in the GrF reinforced adhesive, the crack showed stable crack growth for over $40 \%$ of the total bonded area, where as in the previous micro-DCB samples almost immediately unstable growth occurs. This showed a potential ability of the GrF reinforced adhesive to prevent unstable crack growth and significant potential as a crack arresting reinforcing agent.

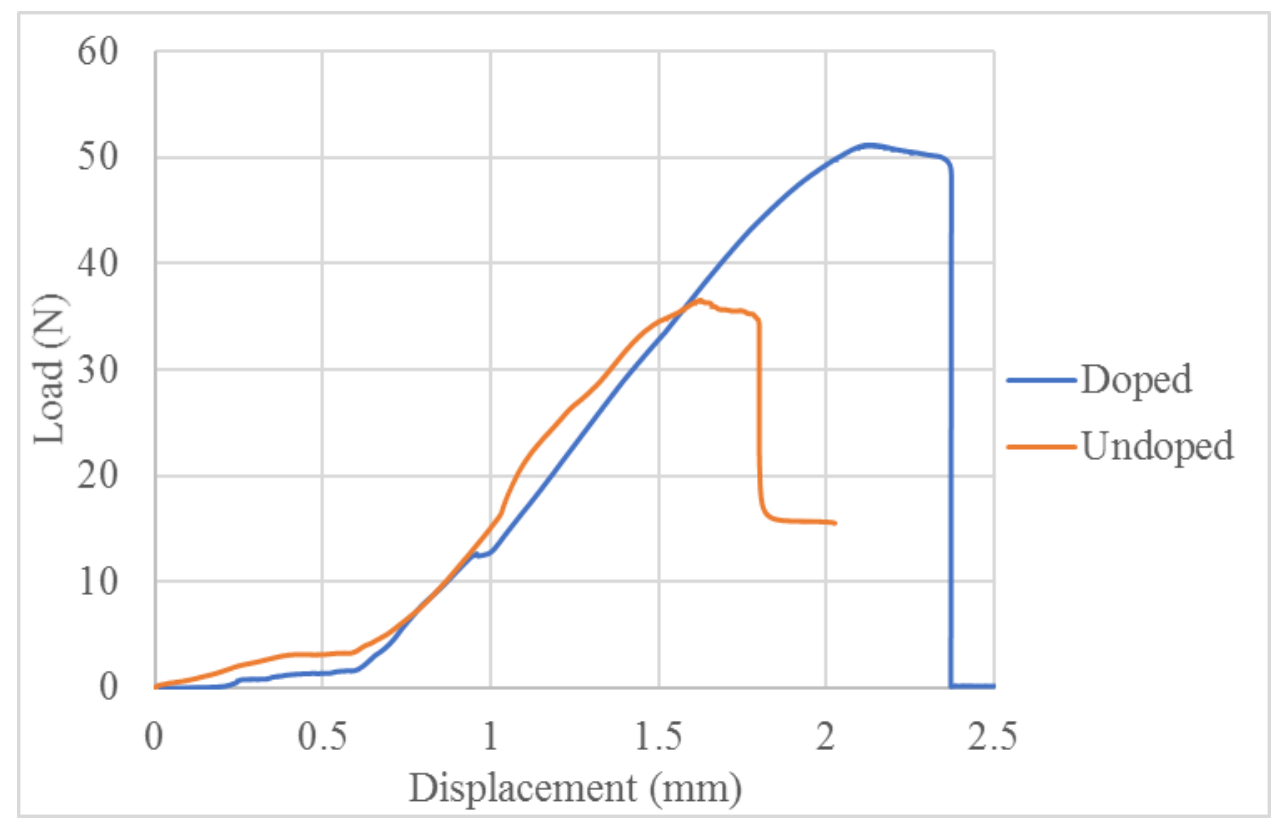

Figure 34. Load displacement curves for micro-DCB, undoped and $G r F$ doped adhesive specimens. 

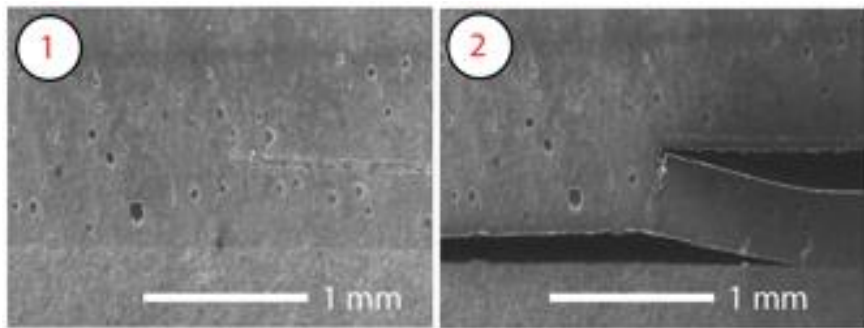

Figure 35. SEM still images of crack propagation during micro-DCB testing of undoped adhesive specimen.
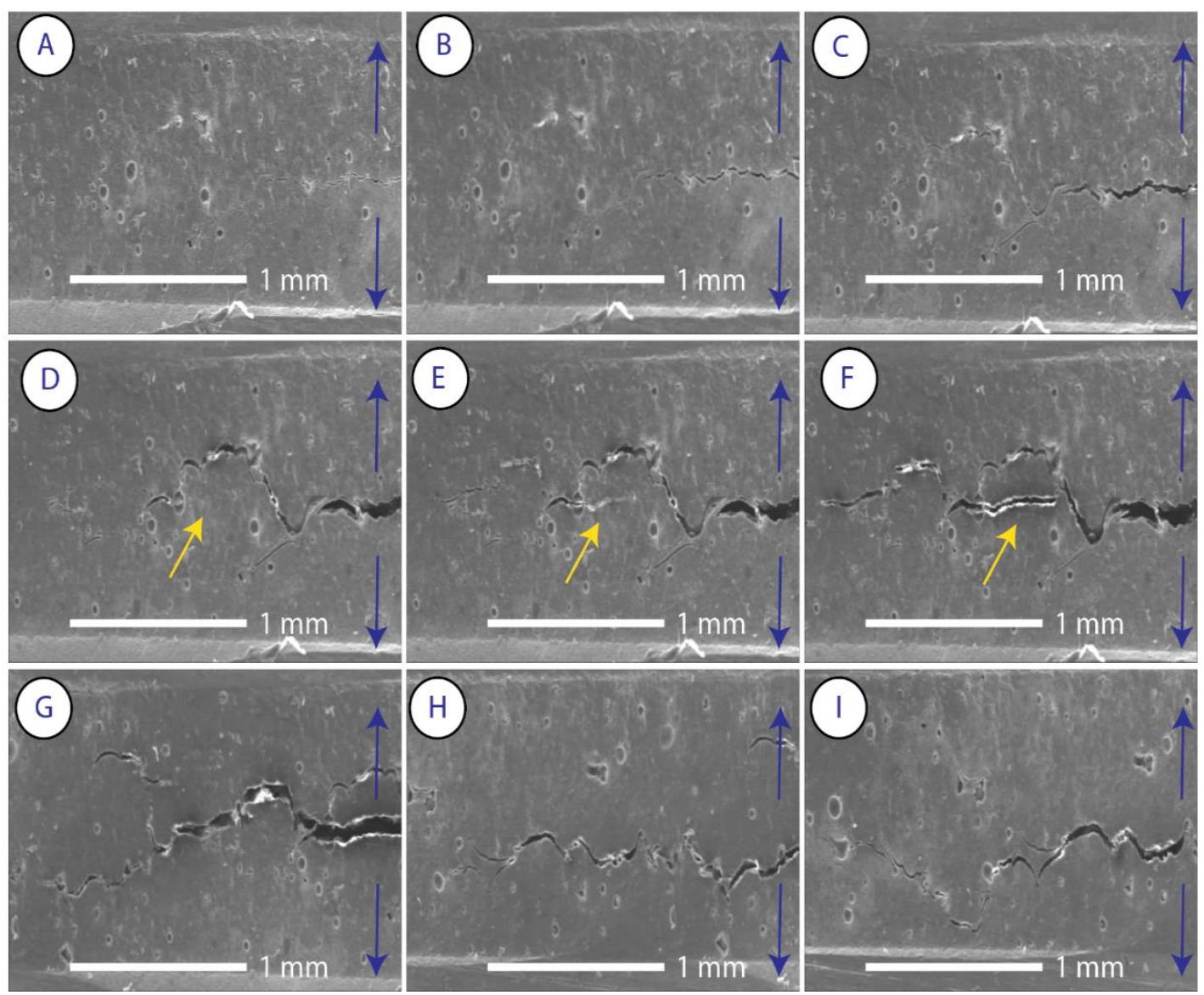

Figure 36. SEM still images of crack propagation during micro-DCB testing of GrF doped adhesive specimen. 


\section{CHAPTER V - CONCLUSIONS}

In this thesis, two different microscale test methods were developed to observe real time imaging of crack propagation in mode I and mode II fracture. To test the mode I fracture within the chamber of a scanning electron microscope (SEM), a micro double cantilever beam test was created. Different reinforcing agents were used with an adhesive to test the different fracture methods ability. Magneto-electric nanoparticles (MENs) were used as a one-dimensional nanoparticle reinforcing agent to create a multifunctional adhesive. Graphene nanoplatelets (GNP) were used as a two-dimensional reinforcing agent. Finally, graphene foam $(\mathrm{GrF})$ was used as a three-dimensional reinforcing agent. The overall finding of this thesis has shown that the micro-DCB and the micro-ENF tests allow for the real-time imaging of mode I and mode II fracturing of a precracked adhesive sample. The tests also allowed for the observation of the mechanisms for crack propagation in different particle reinforced adhesives. The overall findings of each of the different reinforced adhesives are presented by following conclusions:

- Micro-ENF testing showing an increase from $0.50 \mathrm{~kJ} / \mathrm{m}^{2}$ GIIC value for the undoped adhesive to $0.56 \mathrm{~kJ} / \mathrm{m}^{2}$ GIIC value of the MENs doped adhesive, roughly a $12 \%$ increase in mode II fracture toughness.

- SEM still images showed clear interlaminar failure occurring in the undoped adhesive sample, whereas in the MENs doped sample, crack propagation and localized damage outside the plastic zone of crack tip region was observed.

- In the micro -DCB tests for the MENs doped adhesive, the doped samples showed an approximately $33 \%$ higher total fracture energy than the 
undoped samples (measured by the area under the load displacement curves).

- The undoped micro-DCB specimen showed a clear "adhesive" fracture where the crack propagated straight to the adherend. The MENs doped micro-DCB specimen showed at first "cohesive" fracture and then propagating to the adherend and continue in "adhesive" fracture.

- The graphene foam $(\mathrm{GrF})$ doped adhesive showed a $33.68 \%$ improvement from a mode II fracture toughness of approximately $0.71 \mathrm{~kJ} / \mathrm{m}^{2}$ for the undoped samples to approximately $0.95 \mathrm{~kJ} / \mathrm{m}^{2}$ for the doped samples.

- SEM images showed that the GrF reinforced adhesive showed larger crack path than the undoped specimens effectively increasing the fracture toughness. There was also a reduced amount of damage in the GrF reinforced adhesive outside of the plastic zone of the crack tip region.

- In the micro-DCB tests for the GrF reinforced adhesive, the doped samples showed a total fracture energy increase of approximately $71 \%$.

- The GrF reinforced adhesive showed interesting crack propagation where the crack would frequently rise and fall vertically as much as $500 \mu \mathrm{m}$ as well as propagating in the reverse direction.

- Additionally, the GrF reinforced adhesive showed stable crack growth for approximately $40 \%$ of the total bonded area, whereas the undoped specimen unstable crack growth began almost immediately. 


\section{CHAPTER VI - FUTURE WORK}

The goal of this thesis work was to develop the tools necessary to perform fracture tests on adhesives within the chamber of a scanning electron microscope to allow for real time imaging and characterization of the crack behavior in reinforced adhesive samples. The two tests developed in this thesis provide a good start to better understand the fracture behavior of reinforced adhesives. However, there is further work to be done on the understanding of the fracture behavior.

- Fracture Toughness: The fracture toughness of the material is considered to be a material property; however, it has been show previously that geometry of a specimen can influence the fracture toughness calculations. To fully validate the micro-scale fracture toughness tests, a correlation factor between the micro-scale and the macro-scale tests. This can be done by performing the macro-scale, ASTM standard tests for each mode of fracture and comparing the calculated fracture toughness values to the calculated fracture toughness values of the micro-scale tests and developing a correlation factor (or equation).

- Modeling: There are three important facets of any scientific research; theoretical, modeling (or prediction), and experimental. This thesis focus on the experimental portion of scientific research and discusses the theoretical components behind the experiments done. It does not however touch on the modeling aspect of this research. To complete the understanding of the crack behavior in a reinforced adhesive, modeling must be completed. A model must be developed that can accurately predict the crack behavior in reinforced adhesives. The model must consider the material properties of 
both the adhesive and the reinforcing agent as well as the geometry and composition of the reinforcing agent. If a model is developed that can encompass these things based on experimental data, then accurate predictions can be made for varying reinforced adhesives.

- Mode III Fracture: Mode III fracture, the tearing mode, is generally considered to be the most difficult fracture mode to test. Although it may be difficult to experimentally test, it is still an important aspect of understanding the fracture behavior of adhesives and reinforced adhesives. A testing method for mode III fracture should be developed that can be performed in situ like the micro-ENF and the micro-DCB tests. 


\section{REFERENCES}

[1] Lenoe, E.M., Oplinger, D.W., and Burke, J.J. Fibrous Composites in Structural Design. Springer US (1980) 543 - 574

[2] Federal Aviation Administration. Best practice in adhesive-bonded structures and repairs. (DOT/FAA/AR-TN06/57). (2007)

[3] Henkel Loctite. Design guide for bonding metals. (2011)

[4] Crocombe, A.D., and Richardson, G. Assessing stress state and mean load effects on the fatigue response of adhesively bonded joints. International Journal of Adhesion and Adhesives 19 (1999) $19-27$

[5] Piehl, M.J., Bossi, R.H., Blohowiak, K.Y., Dilligan, M.A., \& Grace, W.B. Efficient certification of bonded primary structures. SAMPE Technical Conference Proceedings. Society for the Advancement of Material and Process Engineering (2013)

[6] Janssen, M., Zuidema, J., and Wanhill, R.J. Fracture Mechanics. VSSD (2015)

[7] Hsieh, T.h., A.j. Kinloch, K. Masania, A.c. Taylor, and S. Sprenger. The Mechanisms and Mechanics of the Toughening of Epoxy Polymers Modified with Silica Nanoparticles. Polymer 51.26 (2010): 6284-6294

[8] Bray, D.j., P. Dittanet, F.j. Guild, A.j. Kinloch, K. Masania, R.a. Pearson, and A.c. Taylor. The Modelling of the Toughening of Epoxy Polymers via Silica Nanoparticles: The Effects of Volume Fraction and Particle Size. Polymer 54.26 (2013) 7022-7032

[9] Brooker, R. D., A. J. Kinloch, and A. C. Taylor. The Morphology and Fracture Properties of Thermoplastic-Toughened Epoxy Polymers. The Journal of Adhesion 86.7 (2010) 726-741

[10] Griffith, A.A. The Phenomena of Rupture and Flow in Solids. Philosophical Transactions of the Royal Society A (1921)

[11] Rooke, D.P., and Cartwright, D.J. Compendium of stress intensity factors. HMSO Ministry of Defense Procurement Executive (1976)

[12] Inglis, C.E. Stresses in a plate due to the presence of cracks and sharp corners. Transactions of the Institute of Naval Architects 55 (1913) 219 - 241

[13] Westergaard, H.M. Bearing pressures and cracks. Journal of Applied Mechanics 6 ((1939) A49 - 53

[14] Irwin, G.R. Analysis of stresses and strains near the end of a crack traversing a plate. Journal of Applied Mechanics (1957) 361 - 364

[15] Irwin, G.R. Plastic zone near a crack and fracture toughness. Sagamore Conference (1961) $63-76$ 
[16] Irwin, G.R. Relation of stresses near a crack to the extension force. Structural Congress on Applied Mechanics (1954)

[17] Wells, A.A. The brittle fracture strengths of welded steel plates. Trans Royal Inst Naval Architects (1956)

[18] Wells, A.A. Brittle fracture strength of welded steel plates. Brittle Weld Journal (1961)

[19] Rice, J.R. A path independent integral and the approximate analysis of strain concentration by notches and cracks. Journal of Applied Mechanics 35 (1968) 379 - 386

[20] Rooke, D.P., and Cartwright, D.J. Compendium of stress intensity factor. H.M.S.O. (1976)

[21] Bennett, S.J., Devries, K.L., and Williams, M.I. Adhesive fracture mechanics. International Journal of Fracture 10 (1974) 33 - 43

[22] Dannenberg, H. Measurement of Adhesion. Journal of Applied Polymer Science 5 (1961) $125-134$

[23] Malyshev, B.M., and Salganik, R.L. The strength of adhesive joints using the theory of cracks. International Journal of Fracture Mechanics 1 (1965) $114-128$

[24] Bascom, W.D., Cottington, R.L., Jones, R.L., and Peyser, P. The fracture of epoxyand elastomer-modified epoxy polymers in bulk and as adhesives. Journal of Applied Polymer Science 19 (1975) 2545 - 2562

[25] Kawashita, L.F., Moore, D.R., and Williams, J.G. A protocol for determination of adhesive fracture toughness of flexible laminates by peel testing: mandrel peel method. An ESIS protocol (2005)

[26] Taib, A.A., Boukhili, R., Achiou, S., Gordom. S., and Boukehli, H. Bonded joints with composite adherends. Part 1 . Effect of specimen configuration, adhesive thickness, spew fillet and adherend stiffness on fracture. International Journal of Adhesion and Adhesives 26 (2006) $226-236$

[27] Li, S., Thouless, M.D., Waas, A.M., Schroeder, J.A., Zavattieri, P.D. Mixed-mode cohesive-zone models for fracture of an adhesively bonded polymer-matrix composite. Engineering Fracture Mechanics 73 (2006) 64 - 78

[28] Alsalim, H.S. Constructional adhesives used in the buildings of Babylon. Adhesion 5 (1981) $151-156$

[29] Dorrego, F., Carrera, F., and Luxan, M.P. Investigations on Roman amphorae sealing systems. Materials and Structures 37 (2004) 369 - 374

[30] Delmonte, J. The Technology of Adhesives. Literary Licensing, LLC (2012) 
[31] Kraus, G. et. Al. Adhesion of polyethylene and polystyrene to steel. Journal of Polymer Sciences (1951)

[32] McBain, J.W., and Hopkins, D.G. On adhesives and adhesive action. Journal of Physical Chemistry 29 (1925)

[33] Voyutskii, S.S. Autohesion and Adhesion of High Polymers. Wiley Interscience (1963) 127

[34] Sobieszczanski-Sobieski, J., and Haftka, R.T. Multidisciplinary aerospace design optimization: survey of recent developments. Structural Optimization 14 (1997) 1 - 23

[35] McBain, J.W., and Hopkins, D.G. On adhesives and adhesive action. Journal of Physical Chemistry 29 (1925)

[36] Voyutskii, S.S. Autohesion and Adhesion of High Polymers. Wiley Interscience (1963) 127

[37] Voyutskii, S.S., and Vakula, V.L. The role of diffusion phenomena in polymer-topolymer adhesion. Journal of Applied Polymer Science 7 (1963) 475 - 491

[38] Voyutskii, S.S., Vakula, V.L. Effects of self-diffusion and inter-diffusion in polymer systems. Rubber Chemistry and Technology 37 (1964) 1153 - 1177

[39] Derjaguin, B.V., and Smilga, V.P. Electronic theory of adhesion. Journal of Applied Physics 38 (1967)

[40] Benbow, J.J., and Roesler, F.C. Experiments on controlled fractures. Proceedings of the Physical Society. Section B 70 (1957)

[41] Gillis, P.P., and Gilman, J.J. Double-cantilever cleavage mode of crack propagation. Journal of Applied Physics 35 (1964) 647

[42] Wiederhorn, S.M., Shorb, A.M., and Moses, R.L. Critical analysis of the theory of the double-cantilever method of measuring fracture-surface energies. Journal of Applied Physics 39 (1968) 1569

[43] Mostovoy, S., Ripling, E.J., Bersch, C.F. Fracture toughness of adhesive joints. The Journal of Adhesion 3 (1971) 125 - 144

[44] ASTM Standard D5528-13. Standard test method for mode I interlaminar fracture toughness of unidirectional fiber-reinforced polymer matrix composits. ASTM International, West Conshohocken, PA. (2013).

[45] Nairn, J.A. Energy release rate analysis for adhesive and laminate double cantilever beam specimens emphasizing the effect of residual stresses. International Journal of Adhesion and Adhesives 20 (1999) 59 - 70

[46] ASTM Standard D7905/D7905M-14, Standard Test Method for Determination of the Mode II Interlaminar Fracture Toughness of Unidirectional Fiber-Reinforced Polymer 
Matrix Composites. ASTM International, West Conshocken, PA, 2014. DOI: 10.1520/D7905_D7905M-14, www.astm.org

[47] Mahajan, R. P., Patankar, K. K., Kothale, M. B., Chaudhari, S. C., Mathe, V. L., \& Patil, S. A. Magnetoelectric Effect in Cobalt Ferrite-Barium Titanate Composites and Their Electrical Properties. Pramana - Journal of Physics (2002) 1115-1124

[48] Pankhurst, Q. A., J. Connolly, S. K. Jones, and J. Dobson. Applications of Magnetic Nanoparticles in Biomedicine. Journal of Physics D: Applied Physics 36 (2003)

[49] Nair, Madhavan, Rakesh Guduru, Ping Liang, Jeongmin Hong, Vidya Sagar, and Sakhrat Khizroev. Externally Controlled On-demand Release of Anti-HIV Drug Using Magneto-electric Nanoparticles as Carriers. Nature Communications 4 (2013)

[50] Guduru, Rakesh, Ping Liang, Carolyn Runowicz, Madhavan Nair, Venkata Atluri, and Sakhrat Khizroev. Magneto-electric Nanoparticles to Enable Field-controlled HighSpecificity Drug Delivery to Eradicate Ovarian Cancer Cells. Scientific Reports 3 (2013)

[51] Petcharoen, Karat, and Anuvat Sirivat. Magneto-electro-responsive Material Based on Magnetite Nanoparticles/polyurethane Composites. Materials Science and Engineering: $C 61$ (2016) $312-323$

[52] Wetzel, B., Rosso, P., Haupert, F., Friedrich, K. Epoxy nanocomposites - fracture and toughening mechanisms. Engineering Fracture Mechanics 73-16 (2006) 2375-2398

[53] Hsieh, T.H., Kinlock, A.J., Masania, K., Taylor, A.C., and Sprenger, S. The mechanisms and mechanics of the toughening of epoxy polymers modified with silica nanoparticles. Polymer 51-26 (2010) $6284-6294$

[54] Johnsen,B.B., Kinloch, A.J., Mohammed, R.D., Taylor, A.C-., and Sprenger, S. Toughening mechanisms of nanoparticle-modified epoxy polymers. Polymer 48-2 (2007) $530-541$

[55] Boesl, B., Bourne, G.R., and Sankar, B.V. In situ multiscale analysis of fracture mechanisms in nanocomposites. Composites: Part B 42 (2011) 1157 - 1163

[56] Yang, K.Z. MENs doped adhesive and influence on fracture toughness (Master's thesis). Retrieved from FIU database http://fiu.catalog.fcla.edu/permalink.jsp?27FI034622716

[57] Watring, D.S., Yang, K.Z., Coria, J., Wang, P., Boesl, B., Khizroev, S., and McDaniel, D. Development of a Novel Health Monitoring System for Adhesively Bonded Composite Joints Using Magneto-Electric Nanoparticles. American Society for Composites $31^{\text {st }}$ Technical Conference Proceedings (2016)

[58] Allen, M.J., Tung, V.C., and Kaner, R.B. Honeycomb Carbon: A review of graphene. Chemical Reviews 110 (2009) 132 - 145 
[59] Lee, C., Wei, X., Kysar, J.W., and Hone, J. Measurement of the elastic properties and intrinsic strength of monolayer graphene. Science 18 (2008) $385-388$

[60] Wang, X., Zhi, L., and Mullen, K. Transparent, Conductive Graphene Electrodes for Dye-Sensitized Solar Cells. Nano Letters 8 (2008) 323 - 327

[61] Tang, L.C., Wan, Y.J., Yan, D., Pei, Y.B., Zhao, L., Li, Y.B., Wu, L.B., Jiang, J.X., and Lai, G.Q. The effect of graphene dispersion on the mechanical properties of graphene/epoxy composites. Carbon 60 (2013) 16 - 27

[62] Chatterjee, S., Nafexarefi, F., Tai, N.H., Schlagenhauf, L., Nuesch, F.A., Chu, B.T.T. Size and synergy effects of nanofiller hybrids including graphene nanoplatelets and carbon nanotubes in mechanical properties of epoxy composites. Carbon 50 (2012) $5380-5386$

[63] Wang, Y., Wu, Y., Huang, Y., Zhang, F., Yang, X., Ma, Y., and Chen, Y. Preventing graphene sheets from restacking for high-capacitance performance. Journal of Physical Chemistry: C 115 (2011) $23192-23197$

[64] Emtsev, K.V., et al. Towards wafer-size graphene layers by atmospheric pressure graphitization of silicon carbide. Nature Materials 8 (2009) 203 - 207

[65] Wintterlin, J., and Bocquet, M.L. Graphene on metal surfaces. Surface Science 603 (2009) $1841-1852$

[66] Zhang, H.B., Yan, Q., Zheng, W.G., He, Z., and Yu, Z.Z., Tough graphene-polymer microcellular foams for electromagnetic interference shielding. Applied Material Interfaces 3 (2011) $918-924$

[67] Jeong, Y.R., Park, H., Jin, S.W., Hong, S.Y., Lee, S.S., and Ha, J.S. Highly stretchable and sensitive strain sensors using fragmentized graphene foam. Advanced Functional Materials 25 (2015) 4228 - 4236

[68] Nieto, A., Dua, R., Zhang, C., Boesl, B., Ramaswamy, S., and Agarwal, A. Threedimensional graphene foam/polymer hybrid as a high strength biocompatible scaffold. Advanced Functional Materials 25 (2015) 3916 - 3924

[69] Li, J., Zhao, S., Zeng, X., Huang, W., Gong, Z., Zhang, G., Sun, R., and Wong, C.P. Highly stretchable and sensitive strain sensor based on facilely prepared threedimensional graphene foam composite. Applied Materials and Interfaces 8 (2016) 18954 $-18961$

[70] Wang, J.K., Xiong, G.M., Zhu, M., Ozyilmaz, B., Neto, A.H.C., Tan, N.S., and Choong, C. Polymer-enriched 3D graphene foams for biomedical applications. Applied Materials and Interfaces 7 (2015) 8275 - 8283

[71] Dowling, N.E. Geometry effects and the J-integral approach to elastic-plastic fatigue crack growth. Cracks and Fracture (1976) 